\title{
Use of Retinal Explants to Examine the Effect of \\ Granulocyte-Macrophage Colony-Stimulating Factor on \\ Neurite Growth
}

by

Sonia Hanea

A thesis submitted to the Faculty of Graduate and Postdoctoral Affairs in partial fulfillment of the requirements for the degree of

Master of Science

in

Neuroscience

Carleton University

Ottawa, Ontario

(C) 2015

Sonia Hanea 


\begin{abstract}
Adult mammalian central nervous system (CNS) neurons fail to regenerate after injury. Both the extracellular environment and the intrinsic growth state of neurons affect their ability to regenerate. The cytokine granulocyte-macrophage colony-stimulating factor (GM-CSF), known to promote cell survival, may also activate cellular growth programs. In this thesis, the effect of GM-CSF on CNS neurite growth was investigated. The retina, an easily accessible region of the CNS, was examined. Pieces of retinal tissue - retinal explants - were maintained in culture and varying doses of GM-CSF were applied. The growth of retinal ganglion cells (RGC) neurites was quantified. The results indicated that GM-CSF enhanced lengthy neurite growth in embryonic mouse retinal explants. The retinal explantation technique optimized in this study could be used to test the role of potential agents in growth-promotion. Ultimately, long-distance neuronal regeneration is critical in functional recovery after neural injury.
\end{abstract}




\section{ACKNOWLEDGMENTS}

My sincere thank you to my supervisor Dr. Patrice Smith.

Also, special thanks to Dr. Alfonso Abizaid, Dr. John Stead, Diane Trenouth, Ahmed Almaskut and Dr. Shawn Hayley. Overall, a big thank you to past and current members of the Life Sciences Research Building.

Everyone's support and help have been invaluable. 


\section{TABLE OF CONTENTS}

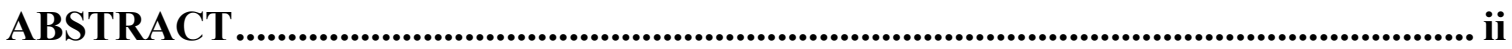

ACKNOWLEDGMENTS .................................................................................................... iii

TABLE OF CONTENTS ............................................................................................ iv

LIST OF FIGURES ................................................................................................................ vi

LIST OF APPENDICES .................................................................................. vii

LIST OF ABBREVIATIONS ............................................................................................ viii

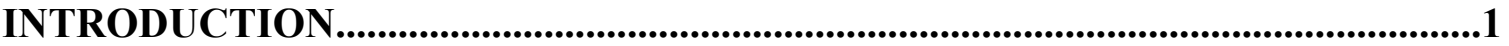

Overview of the visual system ...............................................................................................2

Developmental changes in neuronal growth .......................................................................5

Neuronal regeneration ...............................................................................................................8

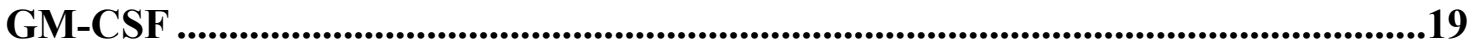

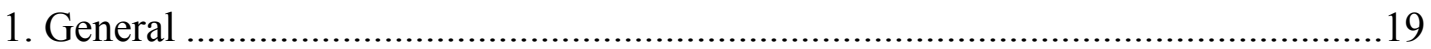

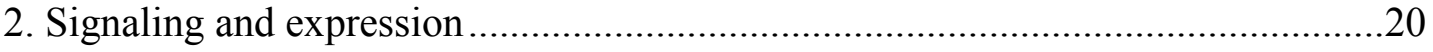

3. Cellular processes in the nervous system .........................................................25

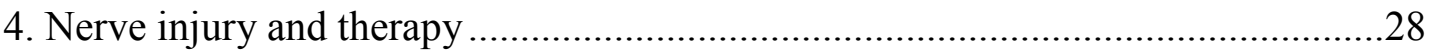

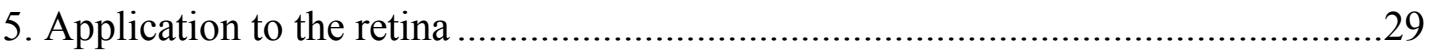

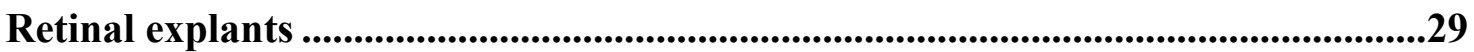

Research objective ...............................................................................................................31

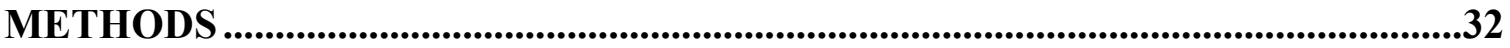

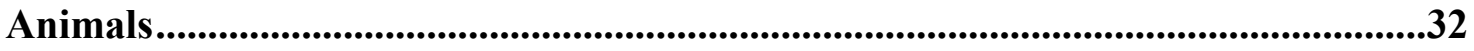

Acid wash of cover slips ......................................................................................................32

Retinal explant preparation ......................................................................................33 
Cover slip preparation

Retinal dissection.

Immunofluorescence ……...........................................................................................................37

Neurite length quantification and statistical analysis ..................................................39

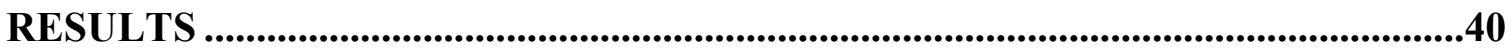

GM-CSF promotes lengthy neurite outgrowth from embryonic mouse retinal explants

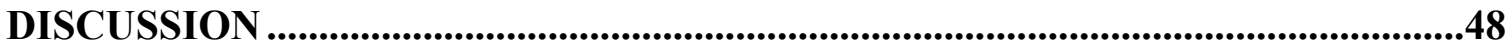

An ex vivo model to study neurite growth ...........................................................................48

GM-CSF: neural effects.....................................................................................................50

Molecules involved in retinal regeneration .......................................................................52

Technical considerations for retinal explants ................................................................54

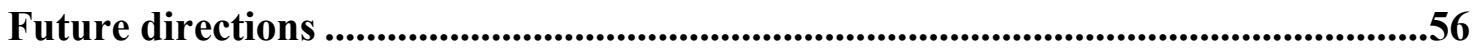

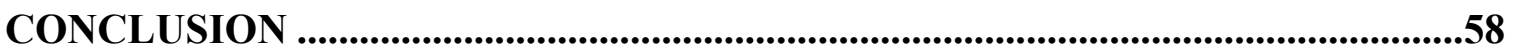

APPENDICES ........................................................................................................................59

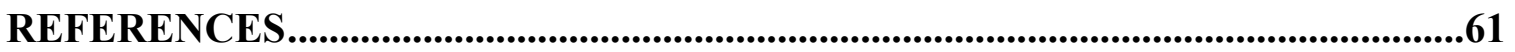




\section{LIST OF FIGURES}

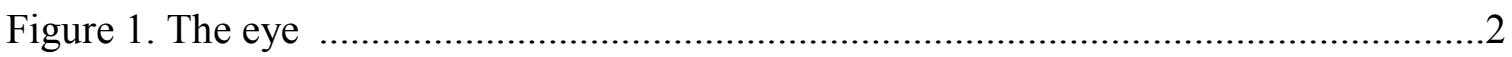

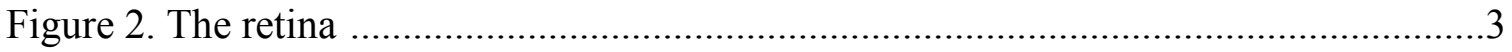

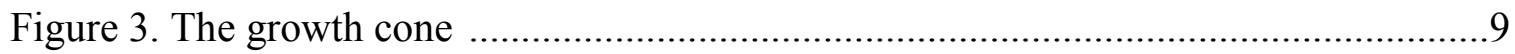

Figure 4. Extracellular barriers to CNS neuronal regeneration .......................................12

Figure 5. Inhibitors of CNS neuronal regeneration ……….........................................14

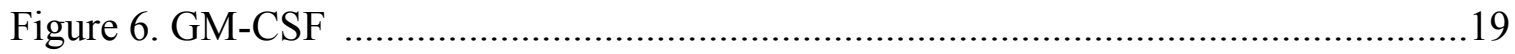

Figure 7. The GM-CSF receptor .........................................................................21

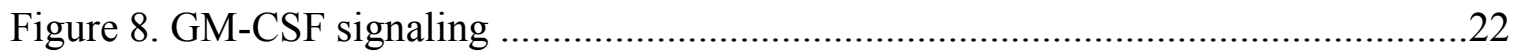

Figure 9. Retinal explant outline ………………………............................................

Figure 10. Retinal explant preparation and examination of neurite growth ......................36

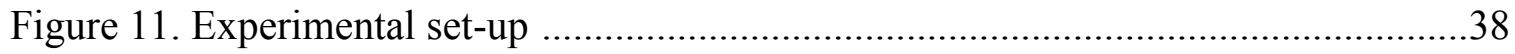

Figure 12. Neurite outgrowth from embryonic mouse retinal explants exposed to different

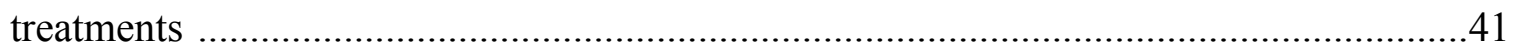

Figure 13. Neurite outgrowth $>50 \mu \mathrm{m}$ from the edges of embryonic mouse retinal explants

Figure 14. Neurite outgrowth $>100 \mu \mathrm{m}$ from the edges of embryonic mouse retinal explants

Figure 15. Neurite outgrowth $>150 \mu \mathrm{m}$ from the edges of embryonic mouse retinal explants

Figure 16. Neurite outgrowth $>200 \mu \mathrm{m}$ from the edges of embryonic mouse retinal explants

Figure 17. Neurite outgrowth $>300 \mu \mathrm{m}$ from the edges of embryonic mouse retinal explants 


\section{LIST OF APPENDICES}

Appendix A. Mean number of outgrowing fibers that grew past different distances from the edges of the retinal explants exposed to different treatments .59

Appendix B. Median number of outgrowing fibers that grew past different distances from the edges of the retinal explants exposed to different treatments .60 


\section{LIST OF ABBREVIATIONS}

\begin{tabular}{|c|c|}
\hline Apaf1 & Apoptotic Protease Activating Factor 1 \\
\hline $\mathrm{Bad}$ & Bcl-2 Antagonist of Cell Death \\
\hline Bax & Bcl-2-Associated X Protein \\
\hline $\mathrm{Bcl}-2$ & B-Cell Lymphoma 2 \\
\hline Bcl-xL & B-Cell Lymphoma-Extra Large \\
\hline BDNF & Brain-Derived Neurotrophic Factor \\
\hline BMSCs & Bone Marrow Stromal Cells \\
\hline BSA & Bovine Serum Albumin \\
\hline cAMP & Cyclic Adenosine Monophosphate \\
\hline $\operatorname{chABC}$ & Chondroitinase $\mathrm{ABC}$ \\
\hline $\mathrm{cKO}$ & Conditional Knockout \\
\hline CNS & Central Nervous System \\
\hline CNTF & Ciliary Neurotrophic Factor \\
\hline $\mathrm{CSF}$ & Colony-Stimulating Factor \\
\hline CSPGs & Chondroitin Sulfate Proteoglycans \\
\hline CREB & cAMP Responsive Element-Binding Protein \\
\hline dATP & Deoxyadenosine Triphosphate \\
\hline DNA & Deoxyribonucleic Acid \\
\hline DRG & Dorsal Root Ganglion \\
\hline E18 & Embryonic Day 18 \\
\hline E20 & Embryonic Day 20 \\
\hline
\end{tabular}




$\begin{array}{ll}\text { FBS } & \text { Fetal Bovine Serum } \\ \text { GCL } & \text { Ganglion Cell Layer } \\ \text { G-CSF } & \text { Granulocyte Colony-Stimulating Factor } \\ \text { GM-CSF } & \text { Granulocyte-Macrophage Colony-Stimulating Factor } \\ \text { GRB2 } & \text { Growth Factor Receptor-Bound Protein 2 } \\ \text { GTP } & \text { Guanosine Triphosphate } \\ \text { GTPase } & \text { Guanosine Triphosphatase } \\ \text { HBSS } & \text { Hank's Balanced Salt Solution } \\ \text { IL-3 } & \text { Interleukin-3 } \\ \text { iPSCs } & \text { Induced Pluripotent Stem Cells } \\ \text { JAK } & \text { Janus Kinase } \\ \text { JAK/STAT } & \text { Janus Kinase/Signal Transducer and Activator of Transcription } \\ \text { KLF } & \text { Krüppel-Like Factor } \\ \text { KO } & \text { Knockout } \\ \text { LIMK } & \text { LIM kinase } \\ \text { MAG } & \text { Myelin-Associated Glycoprotein } \\ \text { MAPK } & \text { Mitogen-Activated Protein Kinase } \\ \text { M-CSF } & \text { Macrophage Colony-Stimulating Factor } \\ \text { mGM-CSF } & \text { Mouse Granulocyte-Macrophage Colony-Stimulating Factor } \\ \text { MPP } & \text { 1-Methyl-4-Phenylpyridinium } \\ \text { min } & \text { Minutes } \\ \text { Messenger Ribonucleic Acid } \\ \text { Mammalian Target of Rapamycin }\end{array}$




\begin{tabular}{|c|c|}
\hline $\mathrm{NgR}$ & Nogo Receptor \\
\hline Nogo & Neurite Outgrowth Inhibitor \\
\hline NPCs & Neural Progenitor Cells \\
\hline NSCs & Neural Stem Cells \\
\hline NT-3 & Neurotrophin-3 \\
\hline OMgp & Oligodendrocyte-Myelin Glycoprotein \\
\hline P8 & Postnatal Day 8 \\
\hline PBS & Phosphate Buffered Saline \\
\hline PFA & Paraformaldehyde \\
\hline PI3K & Phosphoinositide 3-kinase \\
\hline PirB & Paired Immunoglobulin-Like Receptor B \\
\hline PKA & Protein Kinase A \\
\hline PLL & Poly-L-Lysine \\
\hline PNS & Peripheral Nervous System \\
\hline $\mathrm{p} 75^{\mathrm{NTR}}$ & p75 Neurotrophin Receptor \\
\hline pS6 & Phospho-S6 \\
\hline PTEN & Phosphatase and Tensin Homolog \\
\hline $\mathrm{PTP} \sigma$ & Protein Tyrosine Phosphatase $\sigma$ \\
\hline RhoA & Ras Homolog Family Member A \\
\hline RGCs & Retinal Ganglion Cells \\
\hline RPE & Retinal Pigment Epithelium \\
\hline ROCK & Rho-Associated Kinase \\
\hline TROY & Tumor Necrosis Factor Receptor Superfa \\
\hline
\end{tabular}




$\begin{array}{ll}\text { siRNA } & \text { Small Interfering Ribonucleic Acid } \\ \text { SEM } & \text { Standard Error of the Mean } \\ \text { SKPs } & \text { Skin-Derived Precursors } \\ \text { SOCS } & \text { Suppressor of Cytokine Signaling } \\ \text { SOS } & \text { Son of Sevenless } \\ \text { SPSS } & \text { Statistical Package for the Social Sciences } \\ \text { SMI-32 } & \text { Sternberger Monoclonal-Incorporated Antibody } 32\end{array}$




\section{INTRODUCTION}

Santiago Ramón y Cajal's "Degeneration and Regeneration of the Nervous System” was first published in 1913 (Ramón y Cajal, 1968). This work outlined the cellular characteristics of neural regenerative and degenerative phenomena. Regeneration - regrowth after injury - was found to be abortive in the adult mammalian central nervous system (CNS). However, certain findings suggested that regeneration could be manipulated. Namely, fibers of the injured optic nerve - CNS tissue - were able to grow into a peripheral nerve graft (Ramón y Cajal, 1968). These observations were confirmed in the 1980s by Albert Aguayo's group at McGill University. The team determined that some fibers of the injured adult mammalian optic nerve could grow the length of a peripheral nerve graft into their midbrain target, the superior colliculus, and form active synapses there (Aguayo et al., 1987; Vidal-Sanz et al., 1987; Aguayo et al., 1990). Regeneration of injured neurons into peripheral nerve grafts or bridges has also been also noted in other CNS regions, including the spinal cord (Richardson et al., 1980; David and Aguayo, 1981). Studies on regeneration in the visual system, a region of the CNS, have been informative and applicable to other CNS regions. Anatomical and functional similarities exist between the retina - a part of the eye - and the brain and the spinal cord (London et al., 2013). Moreover, not only do CNS pathologies manifest in the eye, but characteristic ocular conditions display neurodegenerative changes (London et al., 2013). Overall, the visual system is easily accessible and amenable to scientific investigations. In this thesis, the visual system has been used as a model to study neuronal regeneration. In particular, the focus has been on evaluating the impact of the cytokine granulocyte- 
macrophage colony-stimulating factor (GM-CSF) on neuronal regrowth using retinal explants.

\section{Overview of the visual system}

The visual system comprises multiple cell types in the eye that coordinate signals to allow visual cues to be registered in the brain. Briefly, vision is possible when light enters the eye through the cornea and reaches the back of the eye, where the retina is located (Fig. 1).

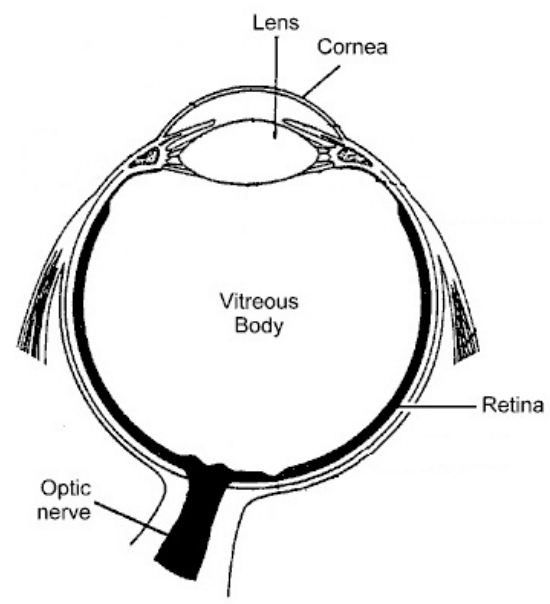

Figure 1. The eye. The eye is made up of several different structures, some of which are outlined here. The cornea is the transparent outer covering of the eye (Gray, 1977). The lens is a capsule-like structure involved in focusing light (Gray, 1977). The vitreous body is a gelatinous structure that is positioned between the lens and the retina (Gray, 1977). 
The retina is the light-processing structure of the eye (Moore \& Goldberg, 2010). The optic nerve transmits electrical signals from the retina to the brain. (Fig. 1 was adapted from Robinson, 1998)

The retina is the neural structure in the eye which processes light. Developmentally, it originates from the neural tube, which gives rise to the entire CNS (Lamb et al., 2007; Cayouette, 2013). The retina is made up of layers of interconnecting neurons and glial cells (Fig. 2).

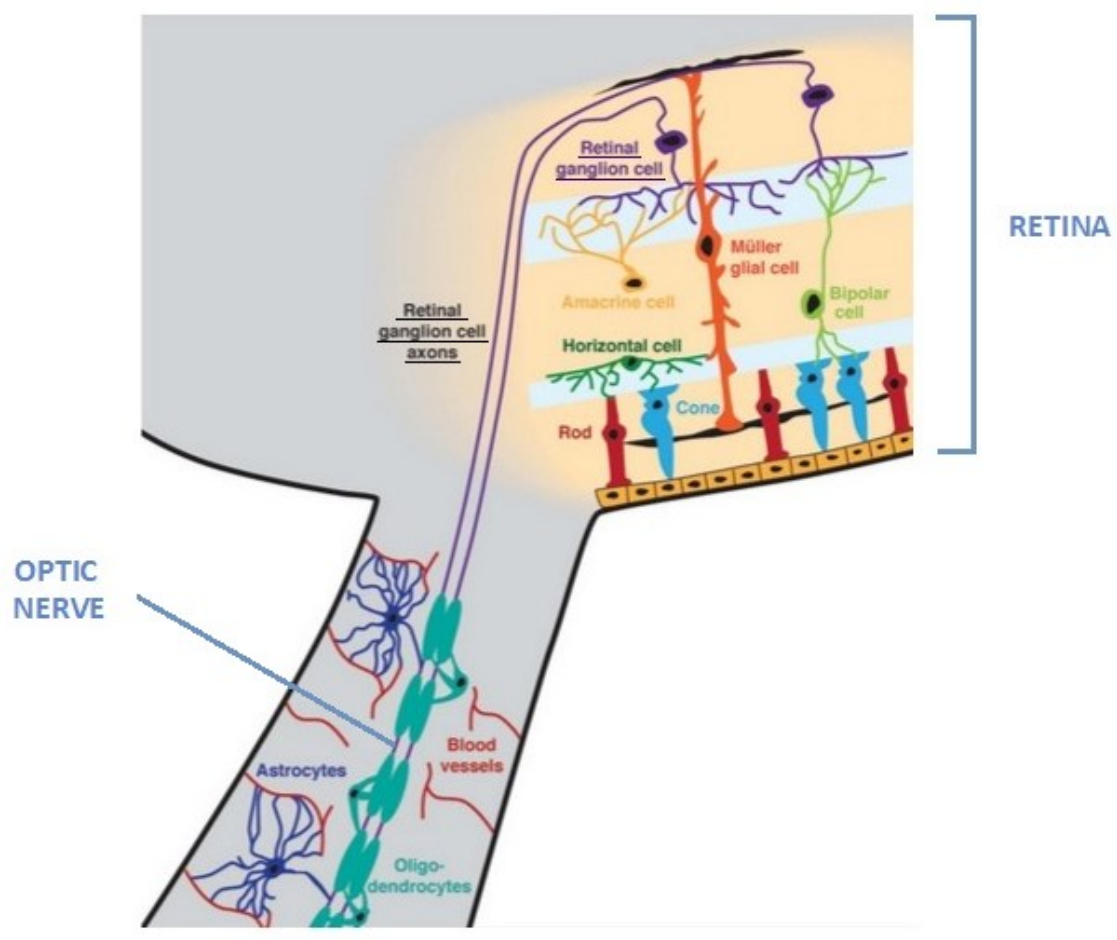

Figure 2. The retina. The retina is made up of several cell types. The rods and cones are photoreceptors. They are located in the outermost retinal layer and they transduce light 
into electrical signals (Moore and Goldberg, 2010). The horizontal, bipolar and amacrine cells are interneurons. They are located in the middle retinal layers and they modulate the electrical activity of the other neurons in the retina (Moore and Goldberg, 2010). The Müller glia cells, which span the retina radially, are involved in supportive functions (Kolb, 2013). Microglia cells, not shown, are also located in the retina and are involved in phagocytic functions (Kolb, 2013). The retinal ganglion cells (RGCs), located in the innermost retinal layer, integrate the electrical signals from the other neurons in the retina. The axons of the RGCs form the optic nerve, which projects to the brain. Oligodendrocytes myelinate the optic nerve fibers (Moore and Goldberg, 2010). Astrocytes play supportive roles for the RGC axons, in particular in the communication between the blood vessels and these fibers (Moore and Goldberg, 2010). Ultimately, the $R G C$ axons provide an electrical output to brain targets (Fig. 2 was adapted from Moore and Goldberg, 2010)

In summary, the retina is made up of many different cell types. The rods and cones are photoreceptors; the horizontal, the bipolar and the amacrine cells are interneurons; the retinal ganglion cells (RGCs) are neurons. Moreover, the Müller glia cells, microglia and astrocytes are glial cells present in the retina (Kolb, 2013). The photoreceptors in the retina transduce light into electrical signals which travel to the innermost retinal layer composed of RGCs. The RGCs are CNS neurons and their axons form the optic nerve, which projects to different brain regions, including the superior colliculus. The relatively few cell types in the retina and their precisely organized layered structure permit not only 
the examination of a particular cell type but its interactions with connecting cells (Cayouette, 2013; London et al., 2013). Moreover, the eye is anatomically accessible; thus administration of target compounds into the eye, to examine neuroprotection and/or regeneration, is relatively simple (Cayouette, 2013; London et al., 2013). The visual system is widely used as a model system to study neuronal growth and regeneration. In particular, the experiments in this study evaluated the growth of RGC projections, using retinal explants - small pieces of retinal tissue that can be cultured and analyzed in an exvivo setting.

\section{Developmental changes in neuronal growth}

Embryonic neurons differ from adult neurons in numerous aspects with respect to their growth. Ultimately, different growth abilities are at play. The growth, both in length and speed, of purified embryonic day 20 (E20) and postnatal day 8 (P8) RGCs was examined over three days (Goldberg et al., 2002). The embryonic RGCs extended longer axons, at faster rates - approximately ten times faster - than the postnatal RGCs (Goldberg et al., 2002). When E20 RGCs were cocultured with amacrine cells or amacrine cell membrane, they displayed decreased growth ability (Goldberg et al., 2002). This suggested that signals from other cells in the retina, in this case amacrine cells, affected the growth state of the RGCs (Goldberg et al., 2002). More insights into growth differences have come from cocultures of retina and superior colliculus. Extensive growth of axons, from the retina into the target superior colliculus, was seen in 
embryonic cocultures; however, minimal growth was observed in postnatal cocultures (Chen et al., 1995). Experiments using cocultures of different ages revealed that the developmental age of the retina, not of the target tissue, determined the growth ability of axons originating from the retina (Chen et al., 1995). In vivo, after neural injury, astrocytes form inhibitory barriers to regrowth (Silver and Miller, 2004). The differential growth responses of neurons to three-dimensional astrocyte cultures were examined (Fawcett et al., 1989). Postnatal dorsal root ganglion (DRG) neurons and adult retinal neurons, in contrast to embryonic ones, failed to grow on older astrocyte cultures (Fawcett et al., 1989). These in vitro cultures mimicked in vivo growth responses. Overall, these data support the notion that there is a developmentally regulated decline in axon growth ability. Accumulating research hypotheses suggest that natural neuronalintrinsic mechanisms, involving cellular signals within neurons, may regulate axon growth ability in the mature CNS.

Intrinsic mechanisms in neurons may be involved in mediating axonal growth ability. In particular, different intracellular signaling pathways are activated (these pathways are further described in the section GM-CSF: signaling and expression). In order to investigate signaling mechanisms, different cell signaling inhibitors were administered to embryonic DRGs and, intact or lesioned, adult DRGs and their growth responses were monitored (Liu and Snider, 2001). In these studies, baseline embryonic DRG growth required the mitogen-activated protein kinase (MAPK) and the phosphoinositide 3-kinase (PI3K) signaling pathways, but regenerative adult DRG growth required the Janus kinase/signal transducer and activator of transcription (JAK/STAT) signaling cascade (Liu and Snider, 2001). Not only has the role of particular 
pathways in neuronal growth been considered, but the contributions of target molecules have been examined. For example, cocultures of retina and superior colliculus were used to investigate the role of B-cell lymphoma 2 (Bcl-2), an anti-apoptotic protein, on neuronal growth (Chen et al., 1997). The developmentally diminished growth ability of RGCs correlated with the developmental decline in Bcl-2 expression in RGCs (Chen et al., 1997). Manipulating Bcl-2 levels in mice, either through knockout (KO) strategies or overexpression, altered axonal growth ability in cocultures of retina and superior colliculus (Chen et al., 1997). In particular, in cocultures from varying developmental stages, RGCs from transgenic mice overexpressing Bcl-2 showed high levels of growth regardless of the developmental age; however, RGCs from wild type mice showed a developmental decline in growth (Chen et al., 1997). These studies pointed to a growthpromoting function for the developmentally regulated molecule Bcl-2. Developmentally, there is a change in the expression of other intracellular signaling molecules in neurons. Of note, mammalian target of rapamycin (mTOR) is a key regulator of protein synthesis in cells. A developmental decline in phospho-S6 (pS6) ribosomal protein, an indicator of mTOR activity, was noted in RGCs and corticospinal neurons (Park et al., 2008; Liu et al, 2010). Another intrinsic player is cyclic adenosine monophosphate (cAMP), a second messenger that activates protein kinase A (PKA), which in turn activates transcription factors, such as cAMP responsive element-binding protein (CREB), which ultimately lead to long-term changes in gene expression (Harel and Strittmatter, 2006). It has been shown that developmentally, cAMP levels decrease in DRGs, RGCs and other neurons (Cai et al., 2001). Also, a developmental decline in the ability of these neurons to grow on certain substrates, including myelin, has been noted (Cai et al., 2001). Modulation of 
the cAMP signaling pathway, using signaling inhibitors or cAMP analogues, affected the growth, both in length and direction, of CNS neurons on myelin substrates (Song et al., 1998; Cai et al., 2001). Screens have been conducted in RGCs in order to identify messenger ribonucleic acid (mRNA) transcripts whose expressions change developmentally - during the time that RGCs lose axon growth ability (Moore et al., 2009). Several candidates have been identified (Moore et al., 2009). Overexpression of one of these candidates, the transcription factor Krüppel-like factor-4 (KLF4), in embryonic RGCs or hippocampal neurons considerably inhibited neurite growth (Moore et al., 2009). The levels of other KLF members have been found to be developmentally regulated in neurons, and overexpression of specific KLFs either promoted or inhibited CNS neurite outgrowth (Moore et al., 2009). Overall, neuronal growth ability varies not only developmentally, but also after injury.

\section{Neuronal regeneration}

It is well established that embryonic growth and neuronal regrowth after injury requires the formation of a growth cone at the tip of the axon (Bradke et al., 2012) (Fig. $3)$. 


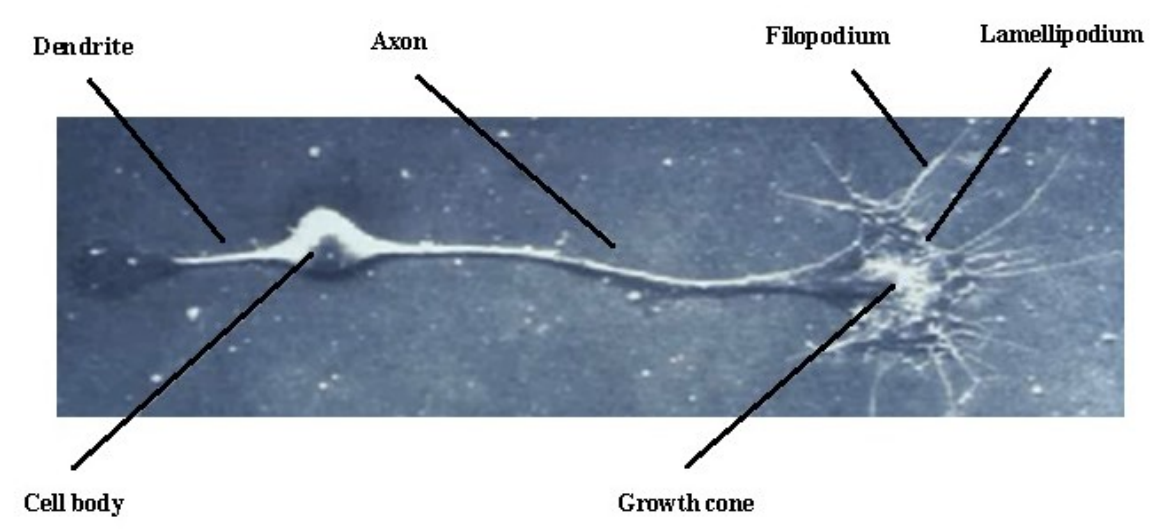

Figure 3. The growth cone. In a neuron, the cell body contains the nucleus, the dendrites receive input from other neurons, and the axon conducts electrical impulses. At the tips of developing or injured axons are enlargements - growth cones. At the leading edge of each growth cone are filopodia, finger-like protrusions, and lamellipodia, sheetlike extensions; these actin-rich structures facilitate the advancement of the growth cone (Lowery and Van Vactor, 2009). During embryonic development or after neuronal injury, axons must grow to their appropriate targets. The growth cone senses guidance cues in its environment and steers the axon accordingly. (Fig. 3 was adapted from TessierLavigne, 2009)

The growth cone is a sensory motile structure which senses molecules in the environment and steers the axon in a given direction. The growth cone is made up of a microtubulerich central domain, a transition domain, and an actin-rich peripheral domain (Lowery and Van Vactor, 2009). Growth cone advancement involves actin polymerization at the leading edge and reduced actin retrograde flow (Brown and Bridgman, 2003). In the 
damaged adult mammalian CNS, neurons typically fail to form growth cones. Rather, end bulbs, that do not permit regrowth, form at the tips of the axons (Tom et al., 2004; Ertürk et al., 2007).

Ultimately, adult mammalian CNS neurons, in contrast to peripheral nervous system (PNS) neurons, fail to regenerate (Huebner and Strittmatter, 2009). Insight into this difference has come from studies on DRGs, neurons which have both central and peripheral processes. Injury to the peripheral branch, prior to injury of the central one, resulted in the activation of specific intracellular signaling cascades and enhanced regeneration of the central branch of the DRGs (Richardson and Issa, 1984; Neumann and Woolf, 1999; Qiu et al., 2002; Qiu et al., 2005). In the PNS, the appropriate growth programs are activated in injured neurons and, overall, the extracellular environment facilitates neuronal regrowth. The diminished regenerative ability of the CNS is mainly attributed to an inhibitory extracellular environment as well as a loss in intrinsic neuronal growth ability.

In particular, the site of a neural injury is characterized by cell loss, neuronal degeneration, demyelination and scarring (Horner and Gage, 2000). Cell replacement techniques involve the introduction of cells at the lesion site. The cell sources vary from Schwann cells - myelinating cells from the PNS, to olfactory ensheating cells, to bone marrow stromal cells (BMSCs), to neural progenitor cells (NPCs) and to stem cells (Tetzlaff et al., 2011). These cells not only perform key regenerative functions, but also provide permissive substrates for neuronal regrowth through the lesion site. Of note, the peripheral nerve grafts used to promote CNS regeneration mainly contained Schwann 
cells (Richardson et al., 1980; David and Aguayo, 1981; Aguayo et al., 1987; Vidal-Sanz et al., 1987; Aguayo et al., 1990). Particular cell replacement strategies have involved the use of skin-derived precursors (SKPs) or Schwann cells, generated from the SKPs or from neonatal sciatic nerve segments (Biernaskie et al., 2007; Sparling et al., 2015). Either cell type was introduced into the injured rodent spinal cord (Biernaskie et al., 2007; Sparling et al., 2015). Generally, remyelination of axons, increased axonal growth within the lesion, enhanced tissue preservation and improved functional recovery were noted in injured animals (Biernaskie et al., 2007; Sparling et al., 2015). Moreover, transplantation studies have also used induced pluripotent stem cells (iPSCs), which can give rise to any cell type. In a recent study, human iPSCs were differentiated into multipotent neural stem cells (NSCs), which could further give rise to neurons or glial cells (Lu et al., 2014). The NSCs were transplanted into the injured rodent spinal cord (Lu et al., 2014). The transplanted cells differentiated, and the resulting neurons sent axons in the lesion site and throughout the spinal cord (Lu et al., 2014). Host axons also grew into the graft; however, it is not clear whether functional connectivity was achieved (Lu et al., 2014). Although ethical issues surround some of the cell sources used in transplantation, cell replacement provides a potential therapeutic strategy in neural injury contexts. Transplantation procedures have been used in combination with other techniques in order to achieve not only neuronal regeneration but also axonal guidance to appropriate targets. In a particular study, rats were lesioned at the level of the spinal cord and BMSCs were transplanted into the lesion site (Alto et al., 2009). Some of these rats were also exposed to a preconditioning peripheral lesion, to stimulate growth programs, and received neurotrophin-3 (NT-3), a potential chemotrophic cue, at target areas in the 
CNS (Alto et al., 2009). In these animals, regenerating neurons appropriately innervated and formed synapses within target brainstem regions expressing NT-3 (Alto et al., 2009). Appropriate axonal guidance, coupled with regrowth, is crucial in achieving functional improvements after neural injury.

Specific cellular and molecular mechanisms underlie CNS injury. At the site of injury, myelin is broken down, reactive astrocytes accumulate, and immune cells infiltrate (Silver and Miller, 2004; Yiu and He, 2006; Raposo and Schwartz, 2014) (Fig. 4).

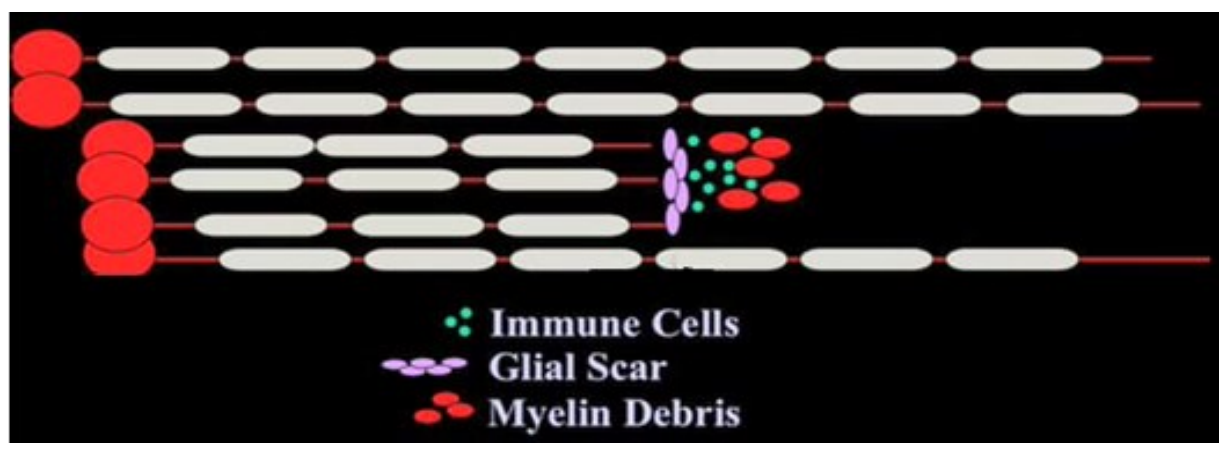

Figure 4. Extracellular barriers to CNS neuronal regeneration. Injury in the CNS results in the impaired regeneration of neurons. It is characterized by the degradation of myelin, the formation of a glial scar made up of reactive astrocytes, and the infiltration of immune cells (Silver and Miller, 2004; Yiu and He, 2006; Fournier, 2009; Raposo and Schwartz, 2014). This extracellular environment is inhibitory to neuronal growth (Nash et al., 2009). (Fig. 4 is from Fournier, 2009) 
Inhibitory molecules, which block neuronal regeneration, are present in myelin and are expressed by reactive astrocytes and immune cells (Filbin, 2003; Yiu and He, 2006; Nash et al., 2009). The three main inhibitors identified in myelin are neurite outgrowth inhibitor (Nogo), myelin-associated glycoprotein (MAG) and oligodendrocyte-myelin glycoprotein (OMgp) (McKerracher et al., 1994; Chen et al, 2000; GrandPré et al., 2000; Kottis et al., 2002; Wang et al., 2002a). Reactive astrocytes make up a glial scar and have been found to secrete chondroitin sulfate proteoglycans (CSPGs), inhibitory extracellular matrix proteins (Silver and Miller, 2004). The myelin inhibitors and the CSPGs bind to their receptors on the cell surface of neurons and trigger intracellular signaling, which ultimately converges on key regulators of the cytoskeleton, including the guanosine triphosphatase (GTPase) ras homolog family member A (RhoA) (Luo, 2002; Filbin, 2003; Guan and Rao, 2003) (Fig. 5). Consequently, cytoskeleton dynamics and neuronal growth behavior are modulated. Active guanosine triphosphate (GTP)-bound RhoA mediates growth cone collapse (Mackay et al., 1995). 


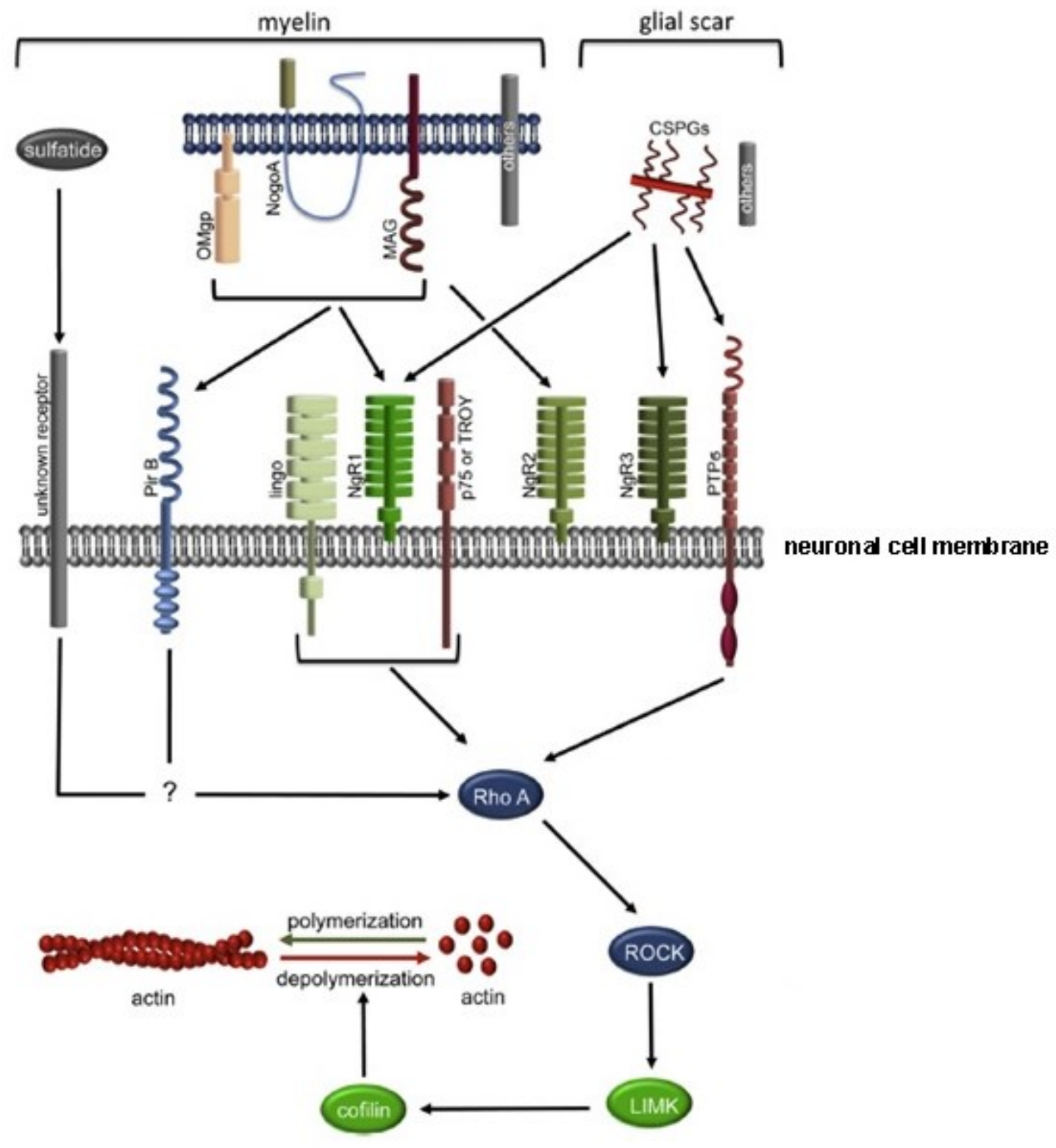

Figure 5. Inhibitors of CNS neuronal regeneration. Multiple growth inhibitors are present at the site of a neural injury. Inhibitors present in myelin include NogoA, OMgp, MAG and sulfatide (McKerracher et al., 1994; Chen et al., 2000; Wang et al., 2002a; Winzeler et al., 2011). CSPGs are inhibitors secreted by reactive astrocytes (Silver and Miller, 2004; Yiu and He, 2006). Other molecules, such as repulsive axon guidance cues, 
are also expressed at the site of injury (Benowitz and Yin, 2007; Giger et al., 2010). Overall, these multiple inhibitors bind to their corresponding receptor(s) on the cell surface of neurons. Several inhibitors can bind to the same receptor(s). For example, NogoA, OMgp and MAG all bind the Nogo receptor 1 (NgRl) (Fournier et al., 2001; Domeniconi et al., 2002; Wang et al., 2002a; Barton et al., 2003). This receptor then forms a functional complex with the protein Lingo and the p75 neurotrophin receptor $\left(p 75^{\text {NTR }}\right)$ or the tumor necrosis factor receptor superfamily member 19 (TROY) (Wang et al., 2002b; Mi et al., 2004; Park et al., 2005). Ultimately, activation of the receptors by extracellular inhibitors results in the stimulation of intracellular signaling cascades within the neurons. Most signaling converges on RhoA, a master regulator of the cytoskeleton (Niederöst et al., 2002; Fournier et al., 2003; Huber et al., 2003; Monnier et al., 2003). Activated RhoA and its downstream effectors promote the depolymerization of actin, which leads to growth cone collapse (Mackay et al., 1995; Luo, 2002). Ultimately, neuronal growth is inhibited. LIMK, LIM kinase; NgR2, Nogo receptor 2; NgR3, Nogo receptor 3; PirB, paired immunoglobulin-like receptor $B ; P T P \sigma$, protein tyrosine phosphatase $\sigma$; ROCK, Rho-associated kinase (Fig. 5 was adapted from Fischer and Leibinger, 2012)

Attempts at promoting CNS regeneration have focused on genetically or pharmacologically manipulating the growth inhibitors and/or their receptors (Schnell and Schwab, 1990; Schnell and Schwab, 1993; Bregman et al., 1995; Moon et al., 2001; Bradbury et al., 2002; GrandPré et al., 2002; Kim et al., 2003; Simonen et al., 2003). For 
example, neutralizing antibodies against the myelin inhibitors or receptor antagonists have been applied at the site of the injury (Schnell and Schwab, 1993; Bregman et al., 1995; Grandpré et al., 2002). Also, the enzyme chondroitinase ABC (chABC) has been used to degrade the CSPGs (Moon et al., 2001; Bradbury et al., 2002; García-Alías et al., 2009; Alilain et al., 2011). Varied levels of regeneration have been noted (Bartsch et al., 1995; Zheng et al., 2005; Tom et al., 2009; Filous et al., 2010; Lee et al., 2010a,b). These results may reflect the redundant actions of these multiple inhibitors and their receptors (Filbin, 2003; Dickendesher et al., 2012). Given this, convergent signaling mechanisms, downstream these inhibitors and their receptors, have been targeted. In particular, RhoA and/or downstream effectors have been antagonized (Lehmann et al., 1999; Dergham et al., 2002; Fournier et al., 2003; Monnier et al., 2003; Fischer et al., 2004b). Overall, enhanced CNS axon regeneration may involve not only attenuating the inhibition from the extracellular environment but also stimulating the intrinsic growth ability of neurons (Benowitz and Yin, 2007; Liu et al., 2011).

The importance of particular stimuli in neuronal regrowth has been elucidated in studies on the visual system. Neurotrophins, in addition to their potential chemotropic role, promote neuronal survival and growth (Chao, 2003). Of note, ciliary neurotrophic factor (CNTF) promoted neurite outgrowth of purified postnatal RGCs (Jo et al., 1999). CNTF expression was found to be upregulated, in retinal astrocytes and Müller cells, by lens injury or intravitreal zymosan injection (Müller et al., 2007; Fischer and Leibinger, 2012). Lens injury involves the puncturing of the lens and the release of lens proteins into the vitreous body (Fischer and Leibinger, 2012). Injection of zymosan, a yeast cell wall preparation, results in the macrophage activation (Fischer and Leibinger, 2012). Both lens 
injury and zymosan were found to promote adult optic nerve regeneration and RGC survival after optic nerve crush (Leon et al., 2000; Yin et al., 2003). The molecular mechanisms underlying these effects have been investigated. Intravitreal injection of $\beta$ or $\gamma$-crystallins, two types of lens proteins, resulted in similar regenerative phenotypes as lens injury; thus these proteins have been implicated in lens injury-mediated neuronal regeneration (Fischer et al., 2008). Of note, lens injury or $\beta$ - or $\gamma$-crystallins injection resulted in CNTF expression and the subsequent activation of the JAK/STAT3 pathway (Müller et al., 2007; Fischer et al., 2008; Müller et al., 2009). Treatment with a Janus kinase (JAK) inhibitor attenuated the neuritogenic effect of lens injury on RGCs (Müller et al., 2007). Moreover, the neuritogenic effects of zymosan have been investigated. A particular zymosan-conditioned media fraction, which promoted the growth of dissociated RGCs, has been identified (Yin et al., 2003). Analysis of this fraction revealed the presence of oncomodulin, a calcium-binding protein (Yin et al., 2003; Yin et al., 2006). In vitro, this molecule promoted the growth of purified adult RGCs in combination with other neuritogenic agents, and also the growth of adult DRGs (Yin et al., 2006). In vivo, inhibition of oncomodulin, using an antagonist or neutralizing antibody, suppressed RGC axonal regeneration induced by zymosan injection or lens injury after optic nerve crush (Yin et al., 2009). Thus, specific stimuli, including inflammatory mediators, have been found to activate neuronal regenerative programs.

The stimulation of neuronal growth programs involves specific intracellular signaling pathways, including cytokine signaling. The activation of these pathways is affected by signaling inhibitors. For example, suppressor of cytokine signaling 3 (SOCS3) inhibits the JAK/STAT pathway, and phosphatase and tensin homolog (PTEN) 
ultimately inhibits the mTOR pathway. Consistently, deletion of SOCS3 or PTEN in adult RGCs has been shown to promote axon regeneration and cell survival after optic nerve crush (Park et al., 2008; Smith et al., 2009). Similar effects have been observed in other CNS neurons (Liu et al., 2010; Zhang et al., 2012; Du et al., 2015). Moreover, codeletion of PTEN and SOCS3 in adult RGCs resulted in a striking synergistic effect on optic nerve regeneration; notably, some fibers reached brain regions and formed active synapses (Sun et al., 2011; Li et al., 2014). Thus, the JAK/STAT and mTOR signaling pathways have been implicated in long-distance CNS regeneration. A downstream effector of these pathways is the anti-apoptotic protein Bcl-2 (Sepúlveda et al., 2007; Asomugha et al., 2010; Choi et al., 2011; Yoon et al., 2012). The sustained axonal growth ability observed in retina-superior colliculus cocultures from Bcl-2 transgenic mice translated to the in vivo setting. Of note, after transection of the optic tract - a continuation of the optic nerve, RGC fibers in wild-type postnatal mice did not cross the lesion; however, fibers in injured transgenic mice overexpressing Bcl-2 crossed the lesion site and invaded the target superior colliculus (Chen et al., 1997). These experiments pointed to a neural regenerative function for Bcl-2. A cytokine which is known to activate the abovementioned signaling mediators, and which has been potentially implicated in regeneration, is GM-CSF (Bouhy et al., 2006; Legacy et al., 2013). 


\section{GM-CSF}

\section{General}

GM-CSF is a monomeric cytokine involved in numerous cellular functions (Murphy, 2012). It was first characterized based on its ability, in vitro, to stimulate the proliferation and differentiation of hematopoietic precursor cells into colonies of granulocytes and macrophages (Burgess and Metcalf, 1980). However, it was found to act not only on progenitor cells, but on mature cells, enhancing their effector functions (Handman and Burgess, 1979; Weisbart et al, 1985; Fleischmann et al., 1986). GM-CSF is one of several colony-stimulating factors (CSFs); their roles broadly include cell survival, proliferation, differentiation and activation (Rasko, 1997) (Fig. 6).

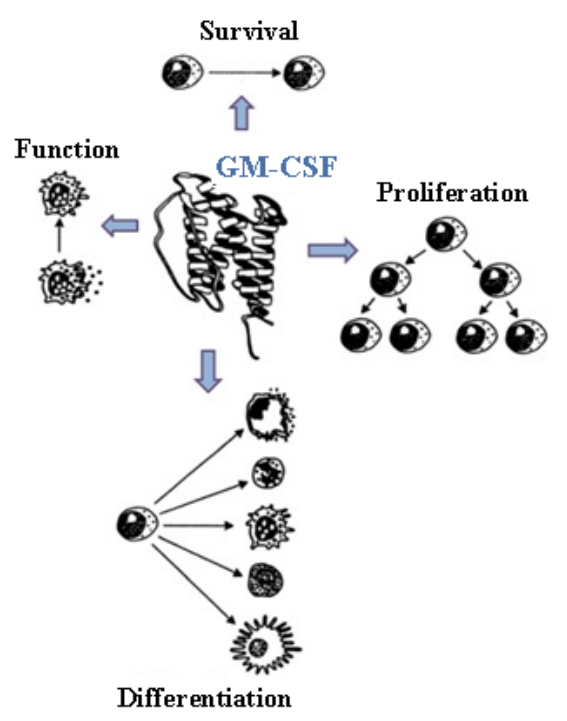

Figure 6. GM-CSF. The cytokine GM-CSF is made up of four alpha helices (Diederichs et al., 1991; Walter et al., 1992). Like other CSFs, it is involved in cell survival, 
proliferation, differentiation and activation (Rasko, 1997). (Fig. 6 was adapted from Rasko, 1997)

More insight into GM-CSF's physiological roles has come from in vivo studies. GM-CSF KO mice exhibited abnormal accumulation of pulmonary surfactant proteins and lipids in the lung tissue; this condition resembled the human disorder pulmonary alveolar proteinosis (Dranoff et al., 1994). Studies on these mice pointed to the abnormal development and functioning of alveolar macrophages (Shibata et al., 2001; Fleetwood et al., 2005). However, in these mice, steady-state hematopoiesis was not affected (Dranoff et al., 1994; Stanley et al., 1994). On the other hand, transgenic mice overexpressing GMCSF displayed macrophage accumulation in the eye, striated muscle, and pleural and peritoneal cavities (Lang et al., 1987). These mice had abnormal retinas, displayed muscle wasting, and died prematurely (Lang et al., 1987). Overall, the appropriate actions of GM-CSF are essential in the correct functioning of vital tissues in the body.

2. Signaling and expression

GM-CSF is made up of four alpha helices and binds to the GM-CSF receptor (Diederichs et al., 1991; Walter et al., 1992). The GM-CSF receptor consists of two 
subunits: the alpha chain, which confers ligand specificity, and the common beta chain, which mediates intracellular signaling (Murphy, 2012) (Fig. 7).

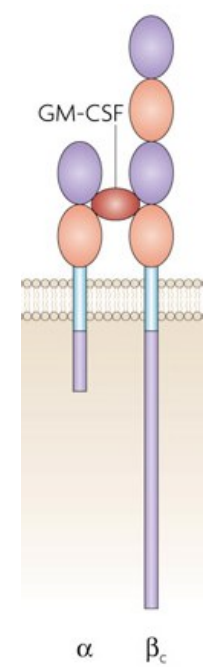

Figure 7. The GM-CSF receptor. GM-CSF binds to the GM-CSF receptor. The GMCSF receptor is a transmembrane receptor consisting of an alpha chain and a common beta chain (Murphy, 2012). (Fig. 7 was adapted from Hamilton, 2008)

Although the binding of GM-CSF to the alpha chain was found to be of low affinity, subsequent binding of this complex to the beta chain transforms it to a high affinity state (Hayashida et al., 1990). Ultimately, the oligomerization of this ligand-receptor complex results in the formation of a functionally active complex (Hercus et al., 2009).

Binding of GM-CSF to its receptor triggers intracellular changes. JAK2, a tyrosine kinase, is associated with the beta chain of the receptor (Quelle et al., 1994). 
Following the oligomerization of the ligand-receptor complex, the JAK2s phosphorylate the beta chains (Hercus et al., 2009). This leads to the activation of three main signaling pathways - the MAPK, PI3K and JAK/STAT pathways - which ultimately regulate gene transcription and/or translation (Fleetwood et al., 2005; van de Laar, 2012) (Fig. 8).

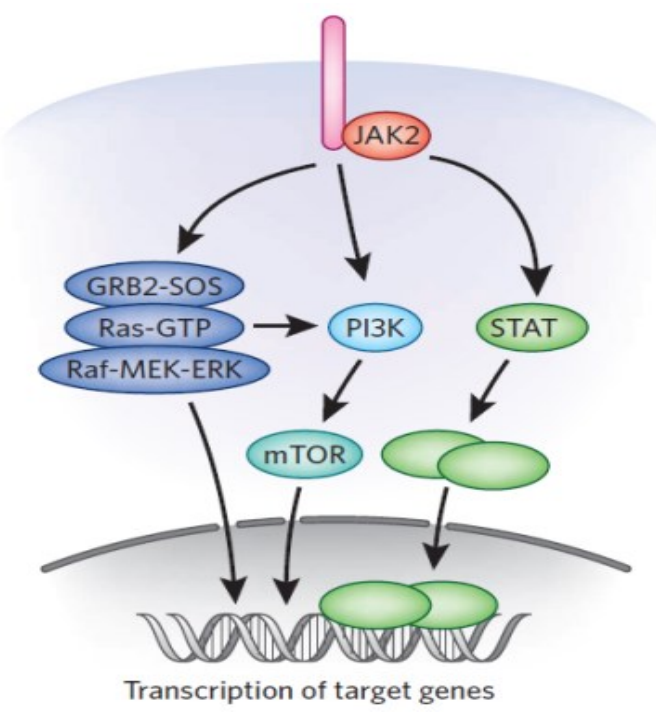

Figure 8. GM-CSF signaling. GM-CSF binds to the GM-CSF receptor and this ligandreceptor complex subsequently oligomerizes (Hercus et al., 2009). The receptorassociated JAK2s are activated and they phosphorylate the common beta chains (Quelle et al., 1994). The MAPK, PI3K and JAK/STAT signaling pathways are then activated (Fleetwood et al., 2005). Ultimately, gene transcription and/or translation are modulated. GRB2, growth factor receptor-bound protein 2 - an adaptor protein; SOS, Son of sevenless - a guanine nucleotide exchange factor. (Fig. 8 was adapted from Fabbro, 2012) 
The JAK/STAT pathway involves the binding of STAT proteins to phosphorylated sites on the beta chain of the receptor (Mui et al., 1995; Murphy, 2012). These STATs are then phosphorylated, form dimers and translocate to the nucleus where they modulate gene transcription (Murphy, 2012). For example, SOCS genes are upregulated and the protein products negatively regulate the JAK/STAT pathway (Rawlings et al., 2004). The MAPK pathway involves the recruitment and activation of the small GTPase Ras (Sato et al., 1993). Ras, in turn, activates a kinase cascade made up of a MAPK kinase kinase, a MAPK kinase and a MAPK (Zhang and Liu, 2002). One such cascade is comprised of Raf-MEK-ERK (Zhang and Liu, 2002). Activated ERK translocates to the nucleus and activates different transcription factors, which subsequently affect gene expression (Zhang and Liu, 2002). The PI3K pathway involves the recruitment and activation of the kinases PI3K, Akt and ultimately mTOR (Hay and Sonenberg, 2004). mTOR plays key roles in protein synthesis (Hay and Sonenberg, 2004). All in all, there is cross-talk between the different pathways (Rawlings et al., 2004). They are involved in many biological functions including apoptosis, cell survival, development, growth, immune function and proliferation (Zhang and Liu, 2002; Shuai and Liu, 2003; Hay and Sonenberg, 2004; van de Laar, 2012).

Of note, GM-CSF has anti-apoptotic effects. Apoptosis, also known as programmed cell death, involves the activation of caspases and ultimately the cleavage of deoxyribonucleic acid (DNA) (Zhang and Xu, 2000; Elmore, 2007). Caspases are particular enzymes which cleave proteins; their own sequential cleavage and activation forms the caspase cascade (Taylor et al., 2008). Apoptosis includes the extrinsic pathway, mediated through transmembrane receptor activation, or the intrinsic pathway, involving 
the release of cytochrome $c$ from mitochondria (Elmore, 2007). Once in the cytosol, cytochrome $c$ binds to apoptotic protease activating factor 1 (Apaf1), an adaptor protein, and deoxyadenosine triphosphate (dATP), thereby forming a complex which cleaves the inactive procaspase 9 to active caspase 9 ( $\mathrm{Li}$ et al., 1997). Caspase 9 subsequently cleaves and activates other caspases, thus initiating the pro-apoptotic caspase cascade (Taylor et al., 2008). Anti-apoptotic molecules, such as Bcl-2 and B-cell lymphoma-extra large $(\mathrm{Bcl}-\mathrm{xL})$, ultimately prevent the release of cytochrome $c$ from mitochondria; in contrast, pro-apoptotic molecules, such as Bcl-2-associated $\mathrm{X}$ protein (Bax), permit the release of cytochrome $c$ from mitochondria (Gogvadze et al., 2006). These pro- and antiapoptotic molecules interact and thus affect each other's functioning (Taylor et al, 2008). For example, pro-apopotic Bcl-2 antagonist of cell death (Bad) binds to and sequesters Bcl-2 and Bcl-xL (Yang et al., 1995). GM-CSF has been found to modulate the levels of both anti- and pro-apoptotic molecules (Huang et al., 2007).

GM-CSF and its receptor are widely expressed in the body, including the nervous system. Outside the nervous system, GM-CSF and the GM-CSF receptor are expressed in a variety of cells, including macrophages (Thorens et al., 1987; Gasson, 1991; Root and Dale, 1999; Fleetwood et al., 2005). Moreover, they are expressed, in vitro, in neuronal and glial cell lines and, in vivo, in various regions of the CNS, both in neurons and glial cells (Baldwin et al., 1993; Sawada et al., 1993; Ha et al., 2005; Reed et al., 2005; Choi et al., 2007; Schäbitz et al. 2008; Schallenberg et al., 2009). Of note, they are expressed in the retina (Schallenberg et al., 2009). In the human fetus, GM-CSF and the GM-CSF receptor are expressed in various organs, including the retina and other neural tissues (Dame et al., 1999). Certain stimuli, such as ischemia, infection and exposure to 
endotoxins, have been show to increase levels of GM-CSF and/or GM-CSF receptors (Burgess and Metcalf, 1980; Schäbitz et al., 2008).

3. Cellular processes in the nervous system

GM-CSF crosses the blood-brain and blood-spinal cord barriers and is involved in neural functions (McLay et al., 1997; Schäbitz et al., 2008; Krieger et al., 2012). In particular, GM-CSF has been shown to elevate choline acetyltransferase activity in septal neurons, to modulate the levels of certain neurotransmitters in the hypothalamus, to affect the electrical activity of neurons, to induce microglial activation, proliferation and changes in morphology, to enhance antigen presentation in neonatal microglia, and to be involved in the regulation of myelin phagocytosis (Kamegai et al., 1990; Suzumura et al., 1990; Fischer et al., 1993; Lee et al., 1994; Saada et al., 1996; Bianchi et al., 1997; Kimura et al., 2000; Ousman et al., 2001; Re et al., 2002; Schermer and Humpel, 2002; Lukashenko et al., 2004).

In vitro and in vivo, GM-CSF plays neuroprotective roles. In neuroblastoma cell lines, NPCs, primary cortical neurons and an RGC cell line, GM-CSF reduced apoptosis induced by cytotoxic agents (Ha et al., 2005; Huang et al., 2007; Schäbitz et al., 2008; Schallenberg et al., 2009; Choi et al., 2011). In primary mesencephalic neurons, GM-CSF had similar neuroprotective effects in the context of the toxin 1-methyl-4phenylpyridinium (MPP ${ }^{+}$(Kim et al., 2009). In vitro, NSCs overexpressing neuronal- 
specific GM-CSF exhibited decreased apoptosis when exposed to cytotoxic conditions (You et al., 2015). Also NSCs transfected with a hypoxia-inducible GM-CSF construct displayed decreased apoptosis, in vitro, and in vivo in the injured spinal cord (Kim et al., 2012). Moreover, GM-CSF treatment after spinal cord injury resulted in a decrease in apoptotic cells, particularly at the lesion epicenter (Ha et al., 2005; Huang et al., 2007). Intravitreal administration of GM-CSF after optic nerve axotomy or ocular cytotoxic insult resulted in increased RGC survival (Schallenberg et al., 2009). Systemic or central administration of GM-CSF protected dopaminergic neurons in Parkinson's disease mouse models (Kim et al., 2009; Mangano et al., 2011).

Cell signaling inhibitors, in addition to other techniques, have been used to delineate the signaling pathways underlying GM-CSF's neuroprotective effect. In particular, the use of cell signaling inhibitors, in combination with small interfering ribonucleic acid (siRNA) knockdown strategies and cytotoxicity trials revealed that the JAK/STAT5-Bcl-2 pathway mediated, at least in part, GM-CSF's anti-apoptotic function in NPCs (Choi et al., 2011). In primary cortical neurons, the PI3K/Akt pathway has been implicated in GM-CSF's anti-apoptotic activity (Schäbitz et al., 2008). Other studies on NPCs have also identified the involvement of the PI3K-Akt pathway and downstream effectors in GM-CSF's anti-apoptotic role (Choi et al., 2014b). In an RGC cell line, the MAPK pathway took part in GM-CSF's anti-apoptotic activity (Schallenberg et al., 2009). All these studies on different cell types have overall implicated the JAK/STAT, PI3K and/or MAPK pathways in GM-CSF’s anti-apoptotic effects. 
Ultimately, GM-CSF's anti-apoptotic mechanisms involve the regulation of the expression of pro- and anti-apoptotic molecules. In GM-CSF-treated spinal cord injured animals, in comparison to controls, there was a decrease in the number of cells that expressed pro-apoptotic proteins and an increase in the number of cells that expressed anti-apoptotic proteins (Huang et al., 2007). Overall, there was an increase in the expression of Bcl-2 and a decrease in the expression of Bax at the site of injury in these animals (Huang et al., 2007). A decrease in Bax expression was recently noted in spinal cord injured rodents transplanted with NSCs overexpressing neuronal-cell specific GMCSF (You et al., 2015). Moreover, in the injured spinal cord of animals transplanted with NSCs, transfected with hypoxia-inducible GM-CSF, the expressions of $B c l-2$ and $B c l-x L$ were increased (Kim et al., 2012). Also, in NPCs and primary cortical neurons, GM-CSF upregulated the expressions of those same two anti-apoptotic molecules (Choi et al., 2011; Schäbitz et al., 2008). In an RGC cell line, GM-CSF induced Bcl-2 expression, but also reduced the expression of the pro-apoptotic protein Bad (Schallenberg et al., 2009). Thus, in various neuronal cell types, GM-CSF's actions resulted in increased expression of anti-apoptotic proteins and decreased expression of pro-apoptotic proteins.

In addition to its various neural functions, GM-CSF may be involved in structural plasticity (Krieger et al., 2012). Of note, GM-CSF KO mice displayed diminished dendritic arborisation and altered spine density and morphology in hippocampal neurons (Krieger et al., 2012). In vitro studies have suggested that GM-CSF is involved in the growth of neural processes from cultured sympathetic neurons, RGCs and superior cervical ganglia (Kannan et al, 1996; Kannan et al, 2000; Legacy et al., 2013). Thus, 
GM-CSF could play a role in neuronal growth-promotion. The objective of this study was to investigate the effect of GM-CSF on CNS neurite growth.

4. Nerve injury and therapy

Generally, GM-CSF may be involved in nerve injury response. For example, after spinal cord injury, in GM-CSF-treated animals, as compared to controls, there was decreased apoptosis at the site of injury, decreased glial scar formation and expression of some CSPGs, increased integrity of axonal and myelin structure, and improved locomotor recovery (Ha et al., 2005; Huang et al., 2007; Huang et al., 2009; Chung et al., 2014). Even delayed administration of GM-CSF after spinal cord injury resulted in enhanced locomotor recovery in paraplegic rats (Bouhy et al., 2006). In a small-scale clinical trial, GM-CSF, in combination with bone marrow cell transplantation, was administered to patients with spinal cord injuries (Yoon et al., 2007). Some neurological improvements, in comparison to controls, were observed in the patients who received an early intervention after injury (Yoon et al., 2007). However, it is still not clear how GMCSF is acting and mediating its effects in nerve injury contexts.

Clinically, GM-CSF is used as a therapeutic agent. Namely, it is administered to improve bone marrow cell reconstitution after bone marrow transplantation, chemotherapy and radiotherapy (Root and Dale, 1999; Franzen et al., 2004). This 
cytokine may have beneficial effects in conditions characterized by lower levels of endogenous GM-CSF.

5. Application to the retina

In normal retinas, from rodents and humans, GM-CSF and the GM-CSF receptor are expressed in RGCs (Schallenberg et al., 2009). However, in glaucomatous retinas, the expressions of GM-CSF and the GM-CSF receptor are downregulated (Schallenberg et al., 2009). In glaucoma or other types of nerve injury, there is the potential of administering GM-CSF and studying its neuroprotective, neuritogenic and/or other effects, as well as its mechanisms of action. Experiments on dissociated RGCs have suggested that GM-CSF could promote neurite growth through an mTOR-dependent pathway (Legacy et al., 2013). Overall, the effects of GM-CSF and the growth of neurons can be investigated in physiologically relevant settings, such as the retinal explantation experimental paradigm.

\section{Retinal explants}

Retinal explantation involves the isolation of the retina and its maintenance intact in culture (Fig. 9). 


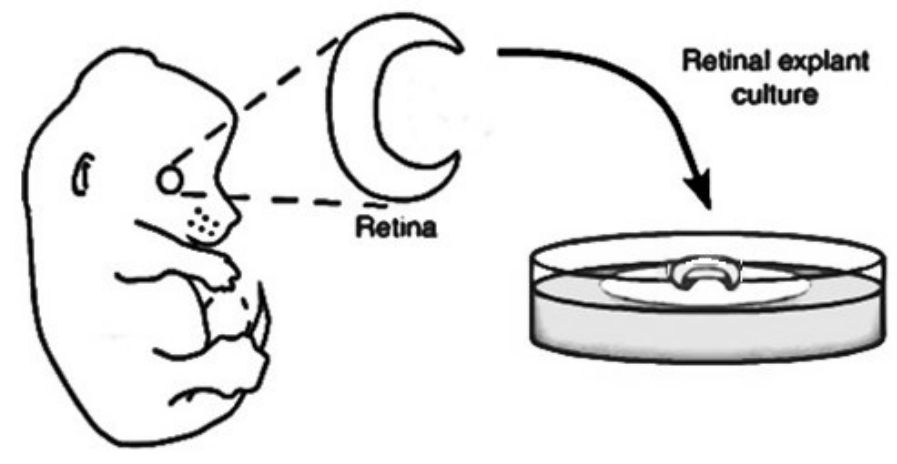

Figure 9. Retinal explant outline. The retina was extracted from, in this case, an embryonic mouse and was maintained intact in culture for several days. (Fig. 9 was adapted from Donovan and Dyer, 2006)

This ex vivo culture has served as an intermediate between in vitro dissociated cell cultures and in vivo animal models (Bull et al., 2011). Namely, in retinal explants, the cellular architecture of the retina and the interactions between the cells have been maintained; thus, the cells have been studied in situ, not in isolation (Bull et al., 2011; Kretz et al., 2007). This method has been used to investigate cellular processes, such as development, growth, neurodegeneration and survival, and techniques, such as cell transplantation, electrophysiology and genetic manipulation (Hatakeyama and Kageyama, 2002; Wang et al., 2002; Cayouette and Raff, 2003; Donovan and Dyer, 2006; McKernan et al., 2006; Koizumi et al., 2007; Kretz et al., 2007; Xin et al., 2007; Johnson and Martin, 2008; Lin et al., 2009; Bull et al., 2011). In particular, retinal 
explants could be used to examine the effects of different molecules, including GM-CSF, on neuronal growth (Böcker-Meffert et al., 2002).

\section{Research objective}

The aim of this study was to investigate the effect of GM-CSF on CNS neurite growth. In particular, the growth of RGCs from retinal explants was examined. Embryonic tissue, given its increased cell survival and growth ability in comparison to adult tissue, was used (Bull et al., 2011). It was hypothesized that if GM-CSF promotes RGC neurite growth, then GM-CSF-treated retinal explants, in comparison to controls, would show increased RGC neurite outgrowth. This hypothesis was tested by applying various doses of GM-CSF to embryonic mouse retinal explants and quantifying neurite outgrowth. 


\section{METHODS}

\section{Animals}

All experiments were performed in accordance with the guidelines of the Canadian Council on Animal Care and with the approval of the Carleton University Animal Care Committee. Experiments were conducted on C57BL/6 mice (Charles River Laboratories, Saint-Constant, Québec).

\section{Acid wash of cover slips}

Cover slips (18mm, Fisher) were immersed in nitric acid in a glass dish for four days. The nitric acid was then removed and the cover slips were washed once with phosphate buffered saline (PBS) and ten times with double distilled water. They were left to dry at room temperature for approximately 30 minutes (min). The dish containing the cover slips was covered with tinfoil and baked overnight in an oven at $150^{\circ} \mathrm{C}$. The following day, the cover slips were transferred into sterile petri dishes. 


\section{Retinal explant preparation}

The protocol described below includes optimized experimental conditions for mouse retinal samples. It is based on techniques that previously involved explant preparation from the embryonic chick retina (Kent et al., 2010).

Cover slip preparation

Acid washed cover slips were placed in the wells of 12-well cell culture plates (Corning) and were coated with $0.01 \%$ poly-L-lysine (PLL, Sigma) for one hour. The PLL was then suctioned off and the cover slips were washed three times with double distilled water. The cover slips were coated with laminin (Corning), $20 \mu \mathrm{g} / \mathrm{mL}$ in double distilled water, and were kept in the tissue culture incubator for $45 \mathrm{~min}$. The laminin solution was then suctioned off and the cover slips were washed once with double distilled water. Prior to placing explants onto the cover slips, the water was suctioned off and a minimal volume of warm culture media was added to the wells.

The culture media consisted of Neurobasal (Invitrogen), 2\% B-27 (Invitrogen), $0.25 \%$ L-glutamine (Invitrogen) and 1\% penicillin/streptomycin (Invitrogen). This media was supplemented with $10 \%$ fetal bovine serum (FBS) (Fisher) (Bouchard et al., 2004). Vehicle (water, Sigma) or recombinant mouse GM-CSF (mGM-CSF, Sigma) was added to the media. The different treatment groups were: vehicle, $0.02 \mathrm{ng} / \mathrm{mL}$ mGM-CSF, $0.2 \mathrm{ng} / \mathrm{mL} \mathrm{mGM}-\mathrm{CSF}, 2 \mathrm{ng} / \mathrm{mL} \mathrm{mGM}-\mathrm{CSF}, 20 \mathrm{ng} / \mathrm{mL} \mathrm{mGM}-\mathrm{CSF}$ and 200ng/mL mGM- 
CSF. The experiments were carried out in a manner that allowed blinded analyses of the acquired data; the investigator was blinded to the treatment groups.

Retinal dissection

Per experimental batch, one pregnant $\mathrm{C} 57 \mathrm{BL} / 6$ mom mouse was euthanized in a carbon dioxide chamber and then cervical dislocation was performed. In mice, most RGCs are born by the embryonic day 18 (E18) developmental stage (Young, 1985; Cepko, 2014). Studies have revealed that these RGCs have high levels of cAMP and can grow well on substrates, including myelin (Cai et al., 2001). In this study, E18 mouse embryos were removed from the abdominal cavity of the mom mouse and placed into cold Hank's Balanced Salt Solution (HBSS, Invitrogen). Decapitation of the mouse embryos was performed using a razor blade (Fisher). Preparation of one retinal explant, from one embryonic retina, took approximately $20 \mathrm{~min}$ (Kretz et al., 2007). As part of this, one retina at a time was dissected from an embryo using spring scissors and Dumont \#5 forceps (Fine Science Tools) (Fig. 10A-C). In particular, the embryonic mouse head was held down with one pair of forceps and the skin covering the embryonic mouse eye was removed using spring scissors. The spring scissors were then used to poke a hole in the eye, at the edge of the corneo-scleral rim (Kretz et al., 2007). A circular opening was made along this rim and the cornea was cut off from the eye. The lens and the vitreous body were then removed using forceps. At times, the retina was still attached to the sides of the vitreous body. In such cases, these points of attachment were cut. Upon the removal of those ocular structures, the translucent retina, attached to the dark retinal 
pigmented epithelium (RPE) below, was visible. A P200 pipette was used to gently eject some HBSS near, but not touching, the retina - particularly in between the retina and RPE. This helped to clear tissue remnants and to detach the retina from the RPE. Once the retina was mostly detached from the RPE, spring scissors were carefully inserted between the two structures and the RGC axons were cut at the optic nerve head. The retina then floated away from the embryonic mouse head and was separately handled. In particular, the dissected retina was cut in a four-leaf clover shape using a razor blade (Fig. 10D). The retina was then spread on a filter membrane (Whatman) with the RGC layer facing upwards (Halfter et al., 1983; Kretz et al., 2007) (Fig. 10E). The edges of the retina were gently pressed onto the filter using forceps. A piece of the retina-filter component, encompassing both central and peripheral retinal regions, was cut using a razor blade. This piece was then placed down, using Dumont \#5/15 forceps (Roboz), onto a cover slip in a well containing a minimal volume, $175 \mu \mathrm{L}$, of warm culture medium (Fig. 10F). The RGC layer was thus in contact with the adhesive substrate on the cover slip. This retinal explant was placed in the tissue culture incubator $\left(37^{\circ} \mathrm{C}, 5 \%\right.$ carbon dioxide) for $30 \mathrm{~min}$. The minimal medium was then suctioned from the well and fresh warm culture medium, a total of $600 \mu \mathrm{L}$, was added, drop by drop - using a P200 pipette - right over the explant. The retinal explants were then maintained in the tissue culture incubator for four days (Smith et al., 2009). The timing of retinal dissection, for example at the beginning or the end of the session, did not affect neurite outgrowth. Throughout the experiments, the treatment order was randomized. 

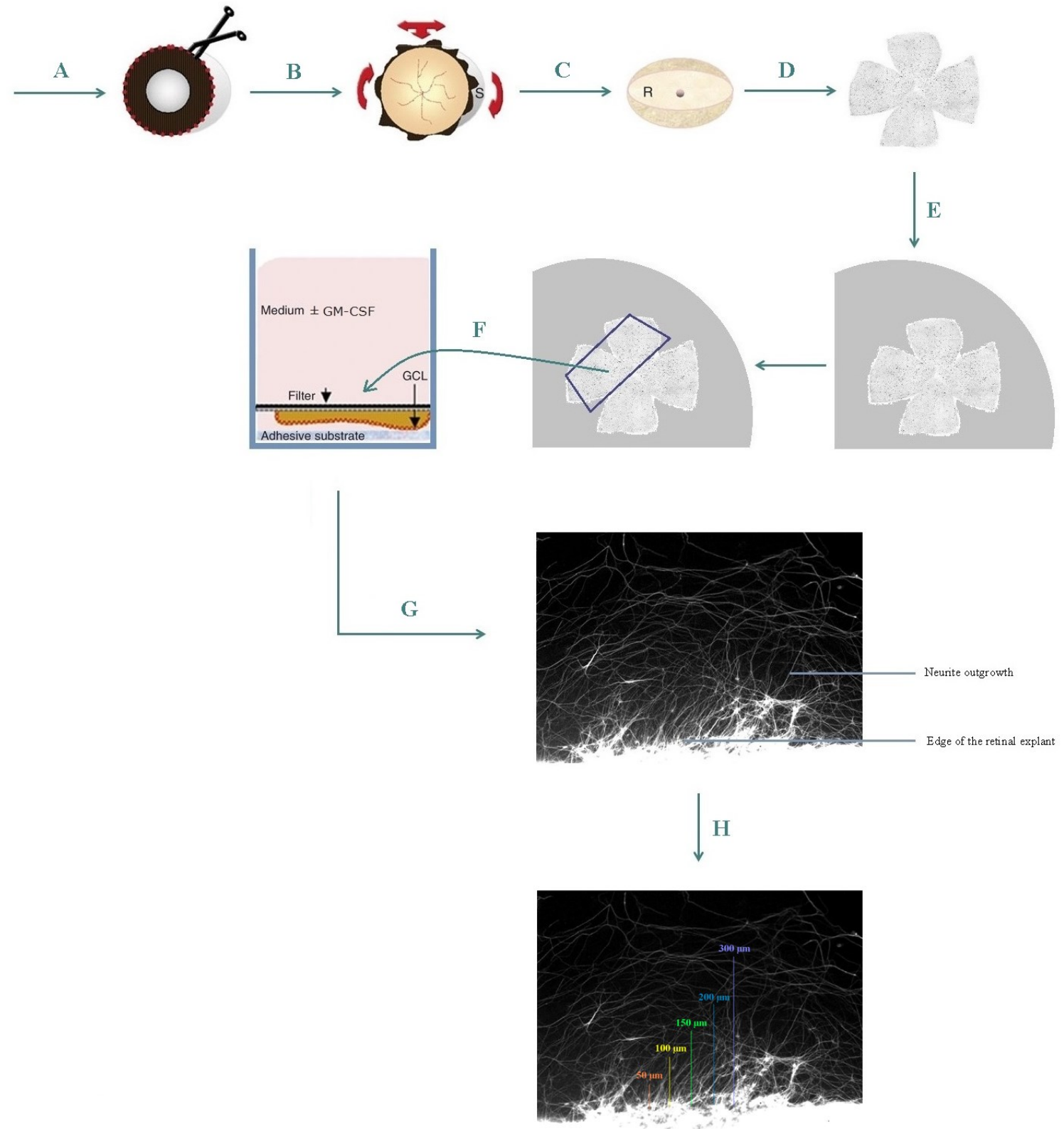

Figure 10. Retinal explant preparation and examination of neurite growth. $(A)$ The eye of an embryonic mouse was opened up. (B) Structures such as the cornea, lens and vitreous body were removed (Kretz et al., 2007). (C) The retina was gently extracted. (D) It was cut in a four-leaf clover shape and $(\boldsymbol{E})$ placed on a filter membrane. The RGC layer faced upwards. (F) A piece of the retina-filter membrane was cut and placed down on a cover slip in a well containing medium. The RGC layer faced the adhesive substrate 
on the cover slip. Thus, an explant was prepared. In this case, the medium contained vehicle or varying doses of GM-CSF. (G) The explants were maintained in the incubator for several days and then immunofluorescence was performed. Anti-BIII tubulin antibody was used. The growth of neurites, from the edge of the explant, was monitored. (H) The number of growing fibers that grew past different distances from the edge of the explant, was quantified, as has been previously demonstrated (Smith et al., 2009). GCL, ganglion cell layer; $R$, retina; S, sclera - connective tissue. (Fig. 10 was adapted from Vidal-Sanz et al., 1987, Kretz et al., 2007, Smith et al., 2009)

\section{Immunofluorescence}

A solution containing 4\% paraformaldehyde (PFA, Sigma) and 20\% sucrose was prepared and heated to $37^{\circ} \mathrm{C}$. This solution, added slowly using a cut P1000 pipette tip at the bottom of each well, formed a layer below the medium in the well; the volume of fix added to each well, $600 \mu \mathrm{L}$, was equal to the volume of medium already present in the well. The explants were fixed for $30 \mathrm{~min}$ at room temperature. The liquid in each well was removed and the explants were washed with 1x PBS. As part of the wash, $600 \mu$ of 1x PBS was added, drop by drop using a P200 pipette, three times every 5 min right over each explant. The explants were then permeabilized with $0.2 \%$ Triton (BDH Chemicals) for 5 min, washed once more with $1 \mathrm{x}$ PBS and subsequently blocked with 5\% bovine serum albumin/PBS (BSA, Sigma) for $60 \mathrm{~min}$ at room temperature. Afterwards, a solution containing 3\% BSA/PBS and anti- $\beta$ III tubulin antibody (Cell Signaling, 1:750)

was added to each well. The explants were placed on a rocker at low speed for $5 \mathrm{~min}$ at 
room temperature and were then incubated for 24 hours at $4^{\circ} \mathrm{C}$. The following day, the explants were washed three times every 5 min with 1x PBS. They were incubated at room temperature for $60 \mathrm{~min}$ in a solution containing 3\% BSA/PBS and Alexa 488 anti-mouse IgG (Cell Signaling, 1:500). The explants were then washed three times every 5 min with 1x PBS. The cover slips, containing the explants, were mounted on glass slides using Fluoromount (SouthernBiotech) and were left to dry overnight. Fluorescence was visualized using an Olympus BX61 microscope. Three fluorescent images were taken per explant at 10x (Smith et al., 2009) (Fig. 10G). Each explant was exposed to a particular treatment condition and represented a sample size of one (Fig. 11).

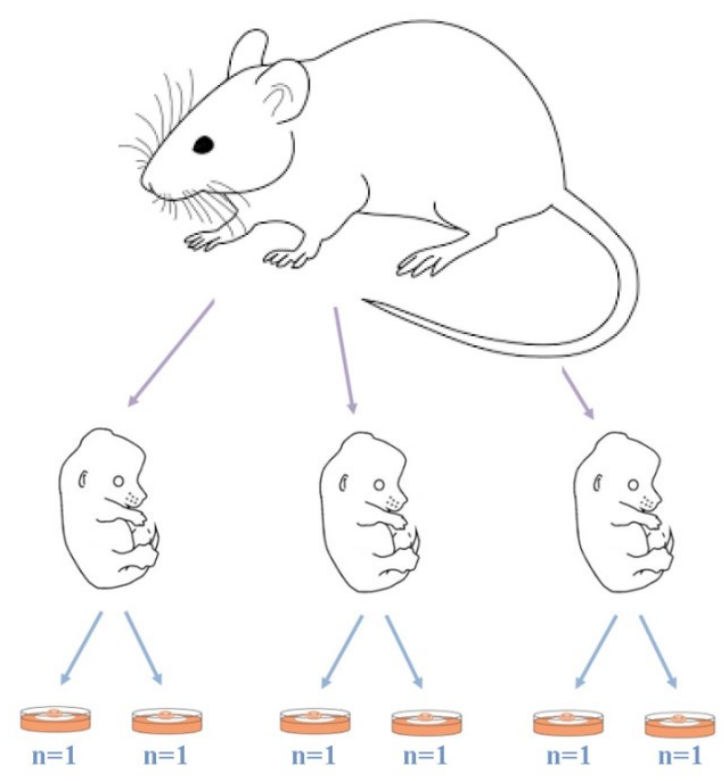

Figure 11. Experimental set-up. One or two eyes per embryo were dissected. One retinal explant per eye was obtained. This corresponded to a sample size of one. Each retinal explant was exposed to a particular treatment. (Fig. 11 was adapted from Donovan and Dyer, 2006, Gwilz, 2013) 


\section{Neurite length quantification and statistical analysis}

The neurites, both axons and dendrites, that grew out from the retinal explants are those of the RGCs (Halfter et al., 1983; Fischer et al., 2004a). Using the Spot software (Diagnostic Instruments, Inc.), the edges of the explants were outlined and the number of fibers that grew past different distances $-50 \mu \mathrm{m}, 100 \mu \mathrm{m}, 150 \mu \mathrm{m}, 200 \mu \mathrm{m}$ or $300 \mu \mathrm{m}-$ from the edges of the explants was quantified as previously demonstrated (Smith et al., 2009) (Fig. 10H). Specifically, the estimated number of outgrowing fibers that grew past a particular distance from the edge of the explant was averaged over three separate images from one explant. The outgrowth data are displayed in Appendices A and B. Data were statistically analyzed using the Statistical Package for the Social Sciences (SPSS, IBM). Given the distribution of the data, the nonparametric Kruskal-Wallis test and its corresponding simultaneous pairwise comparisons test were conducted. The KruskalWallis test has previously been used in the analysis of neurite outgrowth and growth cone

dynamics (Brunet et al., 2005; Leung et al., 2006; Piper et al., 2006; Shimshoni et al., 2009; Hawthorne et al., 2011; Santiago-Medina et al., 2013). 


\section{RESULTS}

\section{GM-CSF promotes lengthy neurite outgrowth from embryonic mouse retinal explants}

In this study, a retinal explant procedure using embryonic tissue was optimized to examine neurite growth. The explants were treated with vehicle or varying doses of GMCSF. $\beta$ III tubulin staining of the retinal explants allowed for the visualization of RGC neurites, both axons and dendrites. Fluorescent micrographs of neurite outgrowth, from explants exposed to the different treatments, were taken (Fig. 12). In the micrographs, there appears to be increased outgrowth in GM-CSF-treated explants in comparison to the vehicle group; in particular, there appears to be increased outgrowth, at greater distances from the edges of the explants, from explants treated with higher doses of GM-CSF. 

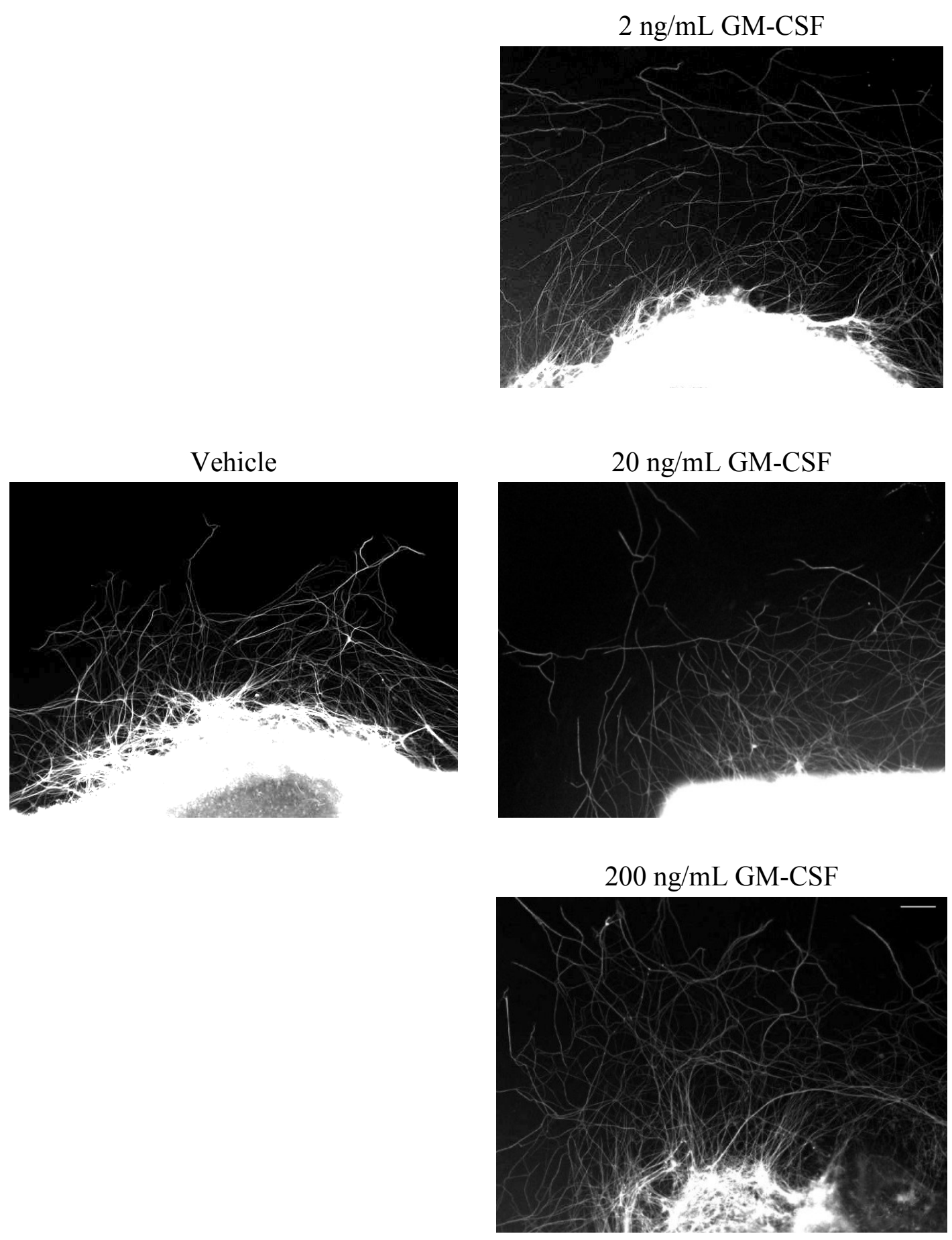

Figure 12. Neurite outgrowth from embryonic mouse retinal explants exposed to different treatments. Representative fluorescent micrographs of $\beta I I I$ tubulin stained 
retinal explants are shown. The explants were exposed to vehicle (water) or varying doses of GM-CSF, as indicated. Scale bar: $50 \mu \mathrm{m}$.

In the fluorescent micrographs, the outgrowth at different distances, greater than (>) $50 \mu \mathrm{m}, 100 \mu \mathrm{m}, 150 \mu \mathrm{m}, 200 \mu \mathrm{m}$ or $300 \mu \mathrm{m}$, from the edges of the explants was quantified. Data are shown as mean estimated number of outgrowing fibers \pm standard error of the mean (SEM) (Figs. 13-17). For all data sets except the first one, there appeared to be a trend of increasing neurite outgrowth as the GM-CSF dose increases. Statistical analysis was performed on the data. For each of the data sets corresponding to the number of fibers that grew past $50 \mu \mathrm{m}, 100 \mu \mathrm{m}, 150 \mu \mathrm{m}$ or $200 \mu \mathrm{m}$ from the edges of the explants, there were no significant differences in outgrowth between the different treatments. For the data set corresponding to the number of fibers that grew past $300 \mu \mathrm{m}$ from the edges of the explants, there was a significant difference between the median estimated number of outgrowing fibers in the $200 \mathrm{ng} / \mathrm{mL}$ GM-CSF group and the median estimated number of outgrowing fibers in the vehicle group. Thus, a comparatively higher dose of GM-CSF was found to enhance the growth of lengthy neurites in embryonic mouse retinal explants. 


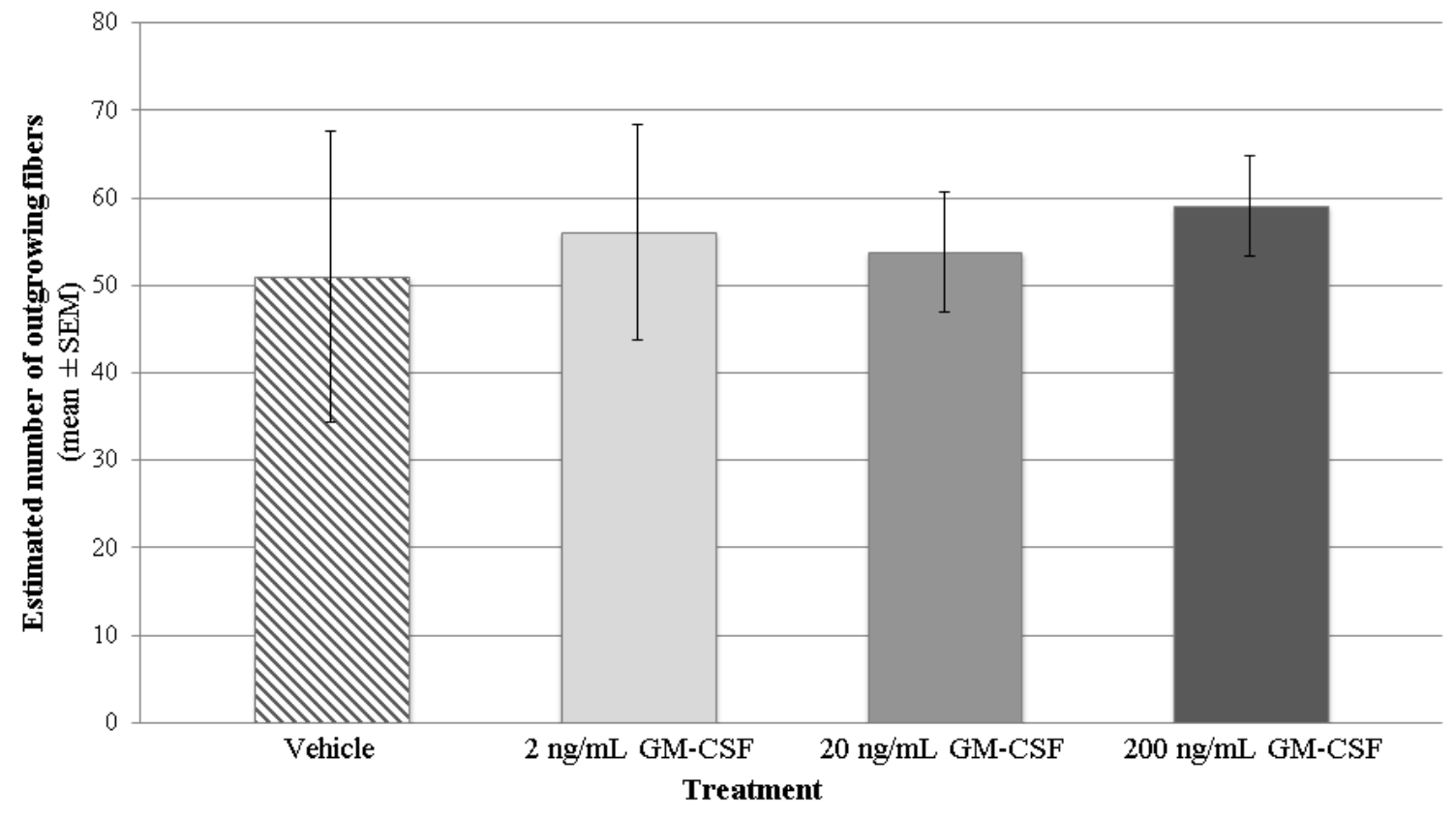

Figure 13. Neurite outgrowth $>50 \mu \mathrm{m}$ from the edges of embryonic mouse retinal explants. Quantification of neurite outgrowth $>50 \mu \mathrm{m}$ from the edges of explants exposed to different treatments. For this length category, there was no statistically significant difference in outgrowth between the different treatments ( $n=4$ per treatment, KruskalWallis test, non-significant: $p>0.05$ ). 


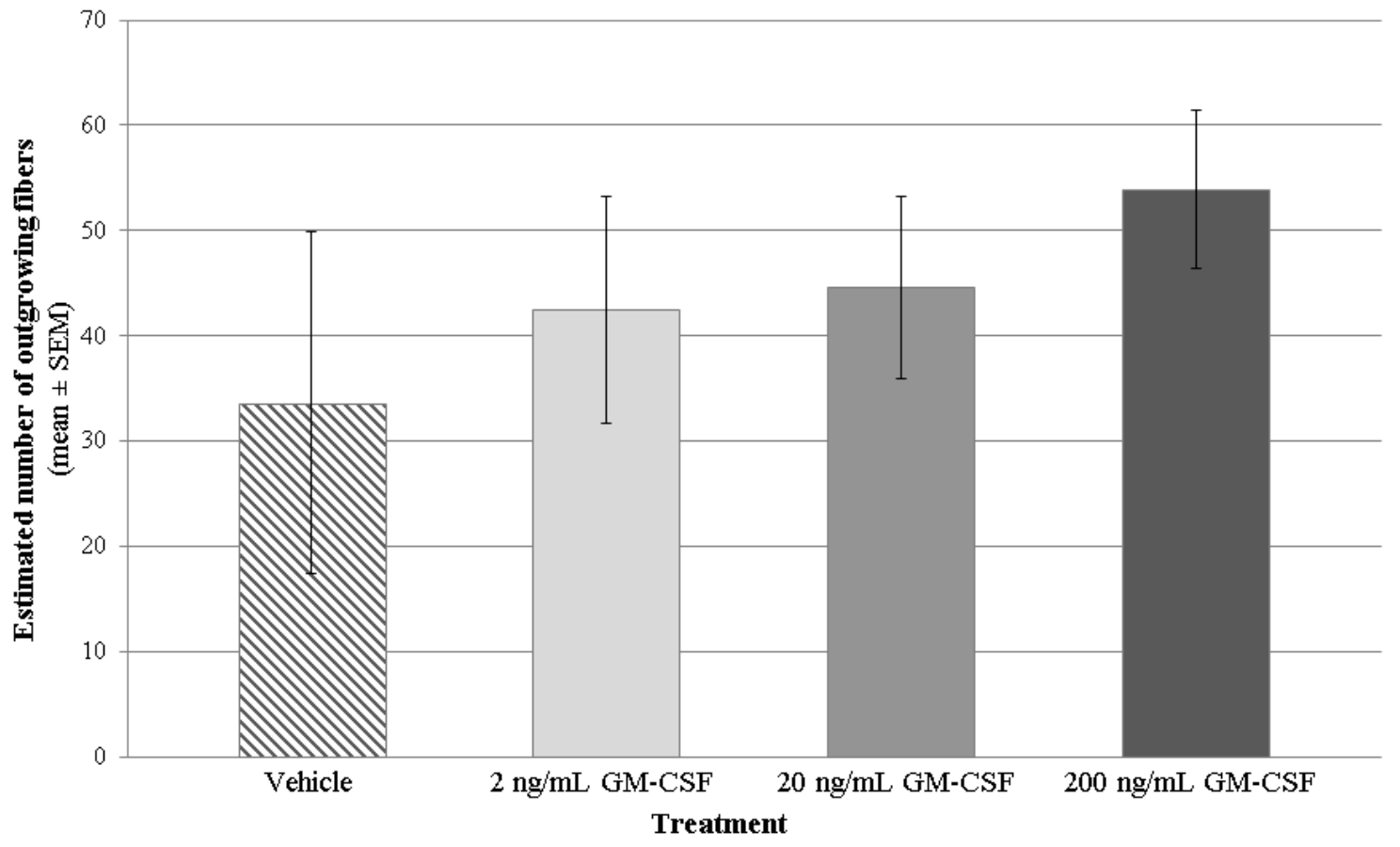

Figure 14. Neurite outgrowth $>100 \mu \mathrm{m}$ from the edges of embryonic mouse retinal explants. Quantification of neurite outgrowth $>100 \mu \mathrm{m}$ from the edges of explants exposed to different treatments. For this length category, there was no statistically significant difference in outgrowth between the different treatments ( $n=4$ per treatment, Kruskal-Wallis test, non-significant: $p>0.05)$. 


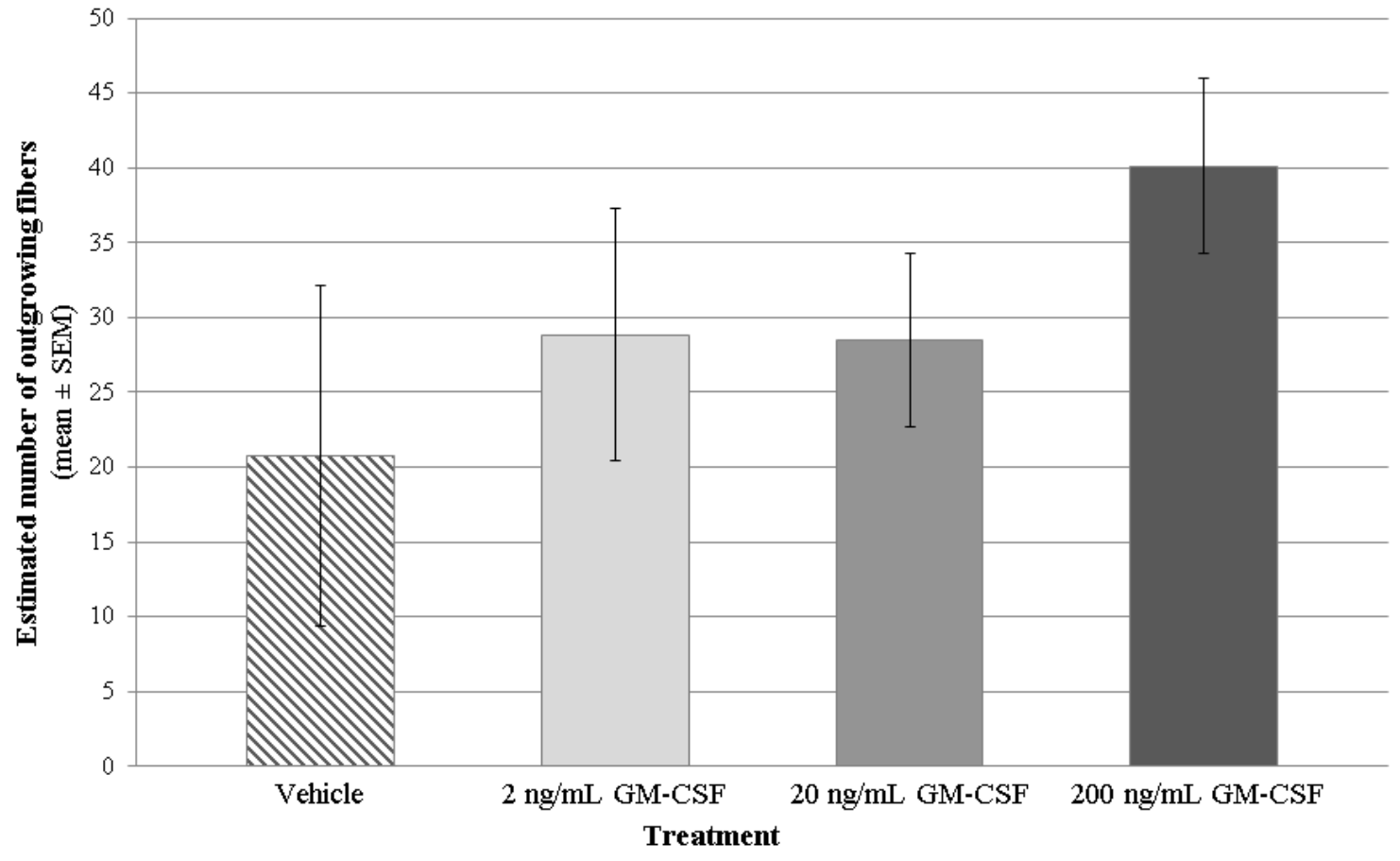

Figure 15. Neurite outgrowth $>150 \mu \mathrm{m}$ from the edges of embryonic mouse retinal explants. Quantification of neurite outgrowth $>150 \mu \mathrm{m}$ from the edges of explants exposed to different treatments. For this length category, there was no statistically significant difference in outgrowth between the different treatments ( $n=4$ per treatment, Kruskal-Wallis test, non-significant: $p>0.05)$. 


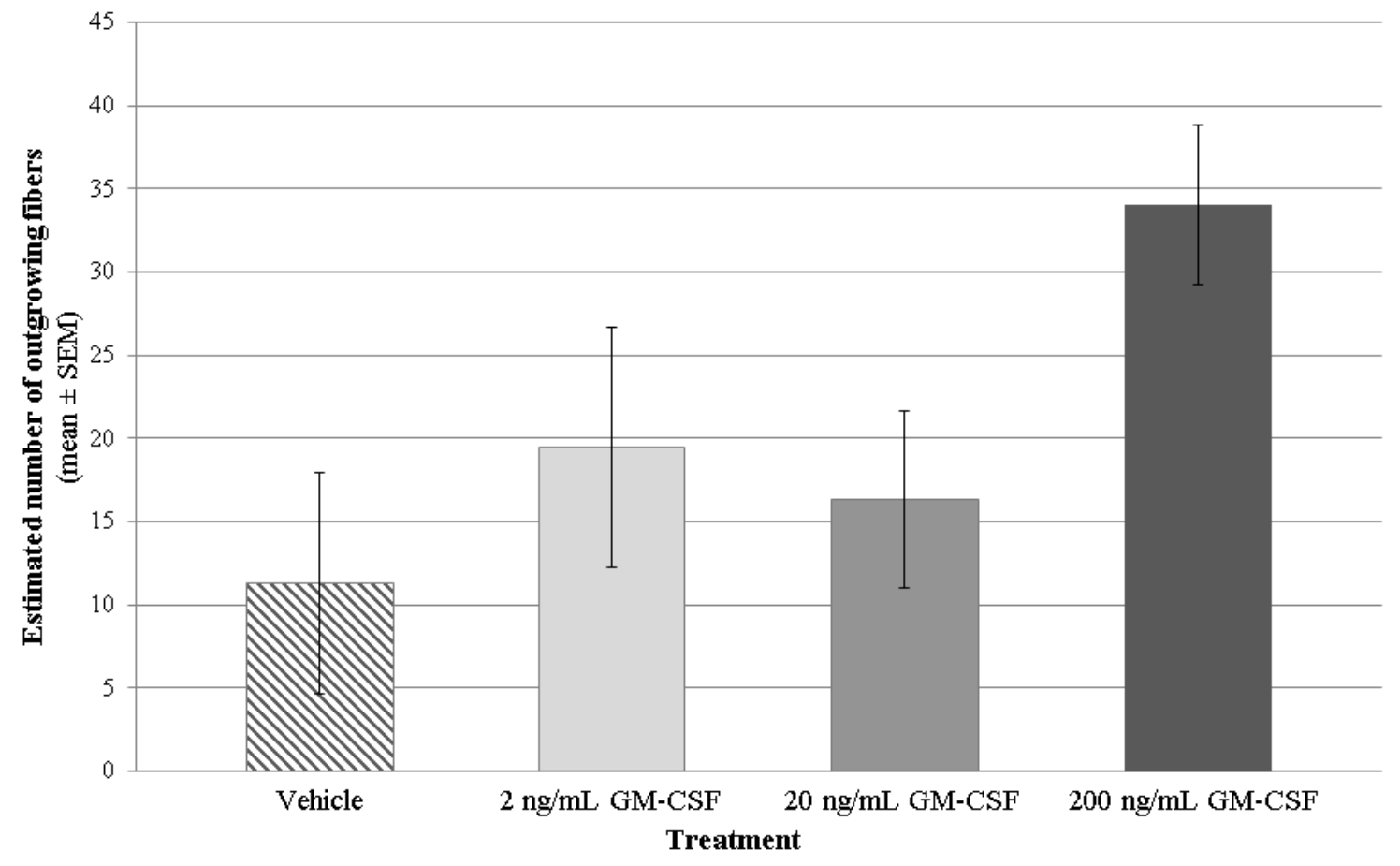

Figure 16. Neurite outgrowth $>200 \mu \mathrm{m}$ from the edges of embryonic mouse retinal explants. Quantification of neurite outgrowth $>200 \mu \mathrm{m}$ from the edges of explants exposed to different treatments. For this length category, there was no statistically significant difference in outgrowth between the different treatments ( $n=4$ per treatment, Kruskal-Wallis test, non-significant: $p>0.05)$. 


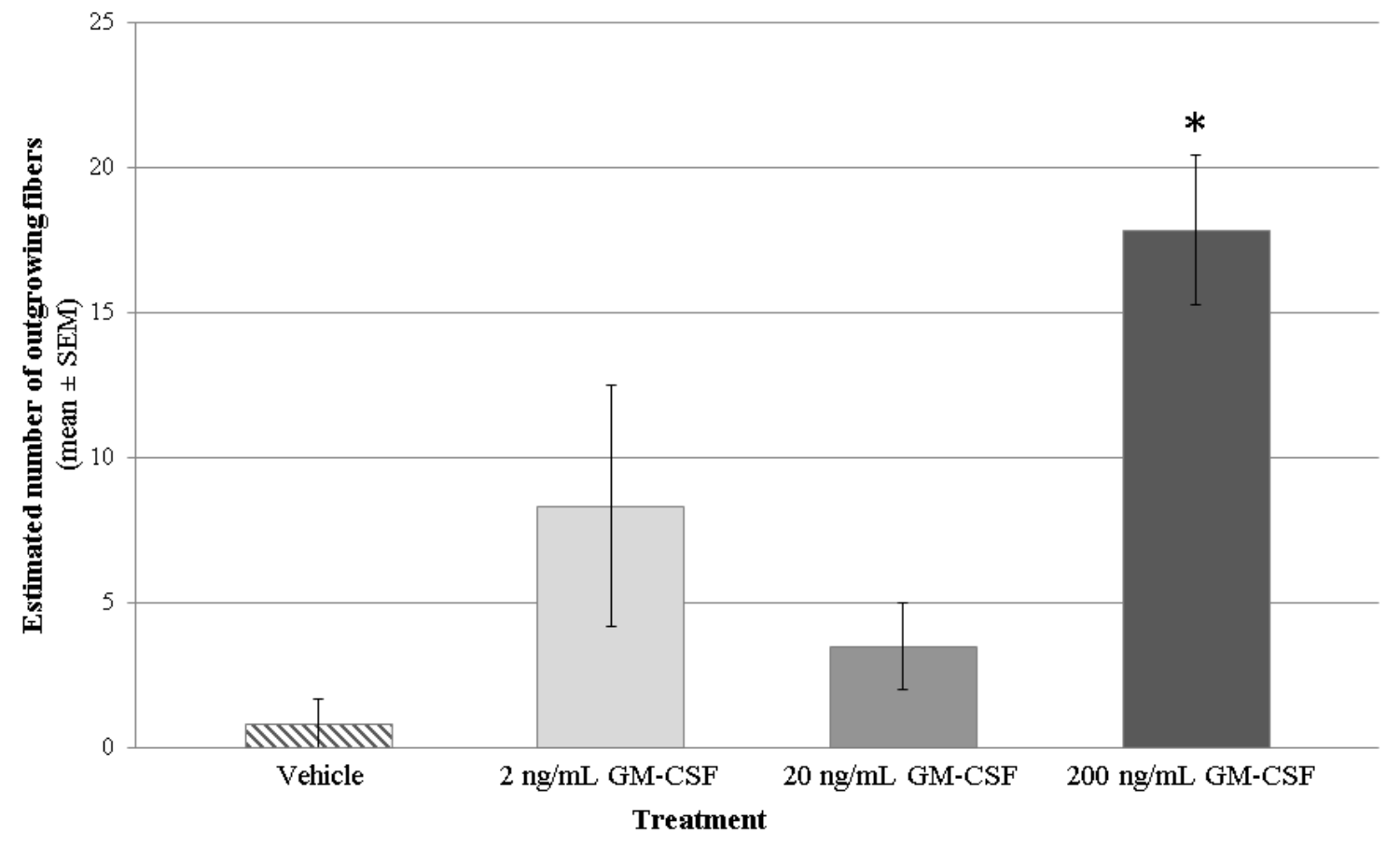

Figure 17. Neurite outgrowth $>300 \mu \mathrm{m}$ from the edges of embryonic mouse retinal explants. Quantification of neurite outgrowth $>300 \mu \mathrm{m}$ from the edges of explants exposed to different treatments. For this length category, there was a statistically significant difference in outgrowth between the different treatments ( $n=4$ per treatment, Kruskal-Wallis test and the corresponding simultaneous pairwise comparison test, significant difference compared to the vehicle group: $\left.{ }^{*} p<0.05\right)$. 


\section{DISCUSSION}

In this study, an optimized method for preparing embryonic mouse retinal explants was described. Our findings indicated that GM-CSF promoted the outgrowth of lengthy fibers from the embryonic mouse retinal explants. Overall, certain considerations needed to be taken into account. In particular, the baseline growth observed in embryonic vehicle-treated explants (Figs. 12-17) made it difficult to identify significant comparisons to GM-CSF-treated embryonic explants. Generally, there was high variability in neurite growth within each treatment. A large sample size would be needed in order to obtain a reliable measure of outgrowth from the explants. Generally, the retinal explant system is highly sensitive, in particular to the contents of the medium, dissection procedure and time (Kretz et al., 2007; Bull et al., 2011). Nevertheless, the explant technique serves as a relevant model of physiological processes.

\section{An ex vivo model to study neurite growth}

In this study, the retinal explant technique was optimized to study the growth of RGCs. Specifically, the embryonic mouse retinal explant procedure described here was initially optimized from a retinal explant method previously used for embryonic chick retina (Kent et al., 2010). Ex vivo findings from mouse retinal explants are reminiscient of the in vivo settings, compared to isolate primary neuronal cultures. Genetically modified mouse models could be used to delineate the molecular mechanisms underlying 
neuronal regeneration, and further investigate the possible contribution of cellular interactions in this process.

In this study, as part of the optimization of the retinal explant technique, all elements of the procedure, such as dissection technique, reagents and time points were closely defined. Medium composition was similar to those previously used for mouse explants (Bouchard et al., 2004; Smith et al., 2009). A dissection technique similar to adult retinal extraction was used; however, the procedure was refined for embryonic tissue (Kretz et al., 2007). With this approach, the RGC layer was in contact with adhesive substrate on the sterile cover slip, like in other retinal explant regeneration studies (Kretz et al., 2007). However, this is unlike retinal explant techniques focused on studying neurodegeneration, in which the RGC layer faces upwards, maintaining contact with the air above and medium below (Kretz et al., 2007; Bull et al., 2011). Thus, given the purpose for using retinal explants, modified methods are perfomed. Moreover, studies focused on analyzing cell dynamics such as cell division in the retina, involve the sectioning of the retina; however, this study was aimed at investigating neurite outgrowth from the retina, so the tissue was mounted intact on a glass slide (Cayouette and Raff, 2003; Jolicoeur and Cayouette, 2014). Different stains are available for use on retinal explants. In this study, anti- $\beta$ III tubulin antibody, widely used to stain retinal explants, was employed (Fischer et al., 2004a,b; Müller et al., 2007; Smith et al., 2009; Bull et al., 2011; Gaublomme et al., 2013). This particular visually clear stain, in combination with the precise placement of the retina - RGC layer downward - on the cover slip, permitted the close examination of neurite growth. Overall, this study included the application of the steps used in other retinal explantation procedures. In particular, the approach was 
refined to study embryonic mouse RGC neurite outgrowth and to limit any disturbances to the explants. Thus, a robust ex vivo system was established. Like in in vitro models, the experimental conditions were precisely controlled. However, unlike in dissociated cell cultures, the cellular connections were maintained (Kretz et al., 2007). This ex vivo model, in which the integrity of the tissue was preserved, mimicked the in vivo setting and provided physiologically relevant and reliable output. Thus, this retinal explant system allowed for the close examination of neurite growth in a physiologically relevant model that included the interactions between the different cell types in the retina, reminiscent of occurrence in an in vivo setting.

\section{GM-CSF: neural effects}

GM-CSF is a potential candidate involved in neuronal growth-promotion. The effects of GM-CSF on neuronal survival and its anti-apoptotic mechanisms have been closely studied (Huang et al., 2007; Schäbitz et al., 2008; Schallenberg et al., 2009; Choi et al., 2011). However, GM-CSF's potential regenerative effects have not been characterized.

Previous in vitro research revealed a dose-dependent effect of GM-CSF on the number of process-bearing sympathetic neurons (Kannan et al., 2000). Studies on dissociated postnatal RGCs suggested that $20 \mathrm{ng} / \mathrm{mL}$ GM-CSF promotes neurite growth (Legacy et al., 2013). It has been difficult to make direct comparisons between these in 
vitro findings and those from the retinal explants in this study since different experimental conditions and designs were used. Retinal explants comprise multiple cell types and include the physiological interactions between these cells types. Therefore, it was not expected that the explants culture experiments would directly mirror the effects observed in an isolated population of cells, in particular of RGCs (Legacy et al., 2013). These differences in experimental conditions, particularly the cellular make-up of retinal explants compared to isolated RGCs from a postnatal stage, limit the direct comparisons between the studies. Indeed, explants represent a closer representation of the physiological setting and results obtained are likely to be more applicable in an in vivo setting. Nevertheless, this study took into consideration the GM-CSF doses used in previous in vitro trials. The lowest doses of GM-CSF used in this study, $0.02 \mathrm{ng} / \mathrm{mL}$ and $0.2 \mathrm{ng} / \mathrm{mL}$, did not result in neurite outgrowth that was significantly different from that observed in the vehicle group (Appendices A, B). In explants, in contrast to dissociated cultures, higher doses of a ligand may be needed in order to target the RGCs and to stimulate a response, given that other cell types within the retina also express the GMCSF receptor (Schallenberg et al. 2009). In particular, in these retinal explants, a dose of $200 \mathrm{ng} / \mathrm{mL}$, of GM-CSF was found to enhance neurite outgrowth. It is possible to speculate that the multiple cellular interactions in the explants could account, at least in part, for the requirement of a comparatively higher dose of GM-CSF to effectuate a regenerative response.

In vivo studies using GM-CSF revealed some functional recovery following neural injury (Ha et al., 2005; Bouhy et al., 2006; Huang et al., 2009); however, it was not known whether GM-CSF acted directly to promote neuronal growth. In these studies, 
it is not clear whether truly regenerating fibers, as opposed to sprouting or spared ones, were analyzed and whether these fibers accounted for the functional behavioral improvements observed. All such cases varied in experimental design, including the GMCSF dose and the source, and the end-product analyzed. Moreover, in these experiments, it was not evident whether GM-CSF acted directly or indirectly on neurons. Of note, GMCSF was found to decrease the expression of growth-inhibitory CSPGs (Huang et al., 2009; Choi et al., 2014a). Also, GM-CSF could have indirectly promoted neurite outgrowth via the secretion of brain-derived neurotrophic factor (BDNF) from other cells types (Bouhy et al., 2006). In the retinal explants in this study, it is not known whether GM-CSF acted directly on RGCs or whether some combination of interactions between cell types in the retina accounted for the effects observed. Indeed, RGCs have been shown to express GM-CSF and GM-CSF receptors, but the expressions in other retinal cell types is not currently clear (Schallenberg et al., 2009). The current thesis research suggests that the preserved retinal architecture in the retinal explants allowed for physiologically relevant molecular interactions to occur.

\section{Molecules involved in retinal regeneration}

Insight into neural regenerative mechanisms has come from the analysis of mRNA and protein expression in uninjured and/or injured neurons (Prokosch et al., 2010; Sun et al., 2011; Belin et al., 2015). Particular molecules associated with regeneration have been identified. A recent study found that the levels of c-myc, a gene encoding a 
transcription factor implicated in cell growth, were downregulated in adult RGCs after optic nerve injury (Schmidt, 1999; Belin et al., 2015). In vivo overexpression of c-myc was found to promote cell survival and axon regeneration after optic nerve injury (Belin et al., 2015). GM-CSF has been known to activate c-myc (Watanabe et al., 1995).

In general, cytokines have been implicated in neuronal regeneration (Prokosch et al., 2010). Activation of cytokine signaling, by inactivation of the inhibitory SOCS3, promoted adult RGC survival and regeneration after optic nerve injury (Smith et al., 2009). Retinal explants from adult SOCS3 conditional KO (cKO) mice showed increased neurite growth in comparison to controls (Smith et al., 2009). Given that GM-CSF activates JAK/STAT signaling, addition of this cytokine to SOCS3 cKO explants may produce a robust phenotype.

GM-CSF is a CSF and it is not the only CSF that acts within the CNS. Macrophage-CSF (M-CSF), granulocyte-CSF (G-CSF) and interleukin-3 (IL-3) have systemic and also central functions (Root and Dale, 1999; Sugita et al., 1999; Schneider et al., 2005; Smith et al., 2013). In particular, some of them could play roles in the context of neural injury (Yagihasi et al., 2005; Luo, 2013; Guo et al., 2014). Of note, GCSF has been found to be neuroprotective after optic nerve injury (Frank et al., 2009). GCSF is known to activate STAT3, which has been associated with neural regenerative phenomena (Tian et al., 1994; Qiu et al., 2005; Bareyre et al., 2011; Sun et al., 2011). Although some of the biochemical mechanisms and functions vary among the CSFs, redundancy does exist. It would be possible to use the retinal explant method outlined in 
this thesis in order to study the regenerative effects of other CSFs, cytokines or potentially applicable molecular targets.

\section{Technical considerations for retinal explants}

There were limitations associated with the preparation of retinal explants. The developmental age studied needed to be taken into consideration. In this study, E18 retinal explants were used. By this developmental stage, most RGCs are born and they display high cell survival and growth ability (Young et al., 1985; Chen et al., 1995; Cai et al., 2001; Goldberg et al., 2002; Rapaport et al., 2004; Cepko, 2014). Overall, embryonic tissue has been particularly amenable to investigation (Bull et al., 2011). Studies on postnatal or adult tissue, which exhibits decreased cell survival and growth ability (Chen et al., 1995; Cai et al., 2001; Goldberg et al., 2002), could help unveil the regenerative effects of potential growth-promoting agents. Even so, studies on adult retinal explants have been complicated by low cell survival and the possible need of a growthconditioning lesion (Bähr et al., 1988; Kretz et al., 2007). Like neurite growth, cell survival is an important determinant in the outcome of neural regenerative attempts. Given that GM-CSF is known to display anti-apoptotic activity, it may have promoted RGC survival in these retinal explants (Huang et al., 2007; Schäbitz et al., 2008; Schallenberg et al., 2009; Choi et al., 2011). However, in this study, the experimental paradigm, which included the use of a filter membrane for retinal attachment and correct 
orientation of RGCs, did not permit the examination of neuronal survival. Further modifications to the procedure may allow for such analysis.

Other technical issues were associated with the retinal explant procedure. A particular challenge was the floating of the explant from the laminin-coated cover slip. This decreased the number of explants that were analyzed. The initial ability of the retina to stick to the filter membrane and the small size of each embryonic retinal explant ultimately affected the adherence of the explant on the cover slip. Also, the region of the retina that was cut may have influenced the neurite outgrowth observed (Kretz et al., 2007). In this study, the area of the cut retina, including both central and peripheral regions, was maintained constant. Moreover, the primary antibody used to stain the explants affected the outgrowth that was visualized. Anti- $\beta$ III tubulin antibody stained all RGC neurites, both axons and dendrites, but it is not RGC-specific; namely, other cell types such as bipolar neurons may have been stained (Sharma \& Netland, 2007; Smith et al., 2009). Nevertheless, in this study, the neurite outgrowth observed was RGC-specific given the consistent maintenance of direct contact between the RGC layer of the explant and the laminin-coated cover slips. In order to examine mainly axonal growth, an antineurofilament antibody could be used (data not shown).

The manual quantification method in this study provided an estimate of the number of fibers that grew past different distances from the edges of the explants. Automated programs for quantifying neurite outgrowth exist (Pool et al., 2008; Gaublomme et al., 2013). However, these methods require a nuclear stain to outline the 
nuclei or the overall explant (Pool et al., 2008; Gaublomme et al., 2013). Such a stain would not be effective with the explant-filter membrane approach used in this study.

\section{Future directions}

Findings from this study suggested that GM-CSF enhances lengthy neurite outgrowth from embryonic mouse retinal explants. They further implicate GM-CSF in neuronal growth and potentially in in vivo long-distance axon regeneration. Future studies can include the use of postnatal or adult neural tissue. Of note, only a small subset of adult RGCs survives in the long-term after optic nerve injury (Berkelaar et al., 1994). Thus, it is of interest to examine the growth of just a subset of RGCs, in particular alpha RGCs. These alpha RGCs are conserved among mammals and account for less than $10 \%$ of all RGCs (Peichl, 1991). Specific markers, such as anti-neurofilament H nonphosphorylated antibody (Sternberger monoclonal-incorporated antibody 32; SMI-32), or particular genetically modified mouse strains can be used to identify these alpha RGCs (Duan et al., 2015). Recent in vivo research revealed that alpha RGCs, in comparison to other RGC subtypes, showed increased cell survival and axon regeneration after optic nerve injury (Duan et al., 2015). Future ex vivo studies can investigate the effect of GMCSF on the growth of alpha RGCs, labeled for example with SMI-32. In most cases of neural injury, long-distance regrowth to the appropriate target is essential for functional recovery. Our ex vivo study suggests a potential role for GM-CSF in the enhancement of the growth of long neurites. GM-CSF's neuronal regenerative effects could be further 
examined in vivo, in models of neural injury. These in vivo approaches, including optic nerve injury and administration of GM-CSF, could provide definitive results on the effects of GM-CSF on the survival and axon regeneration of all RGCs or just a subset, such as alpha RGCs. Such techniques could potentially be coupled with the use of SOCS3 and/or PTEN cKO mice, which have been shown to have enhanced capacities for axon regeneration (Park et al., 2008; Smith et al., 2009; Sun et al., 2011). Combinatorial approaches could also include the targeting of growth-inhibitory intracellular pathways, such as the RhoA signaling pathway (Lehmann et al., 1999; Fischer et al., 2004b; Bertrand et al., 2005). Overall, in order to check for functional regeneration, electrophysiology and/or visual behavior tests can be performed (Horner and Gage, 2000; Heiduschka et al., 2005; de Lima et al., 2012). 


\section{CONCLUSION}

This study investigated the role of GM-CSF on CNS neurite growth. A retinal explant procedure was optimized to examine the growth of embryonic RGCs. The results indicate that GM-CSF enhances the outgrowth of long neurites from embryonic mouse retinal explants. Future GM-CSF studies can be performed on postnatal and/or adult neural tissue and in in vivo settings. Moreover, the retinal explant procedure described here could be used to test the neuronal growth effects of other potential therapeutic agents. The results from retinal explant investigations are applicable to other CNS regions and can help inform future preclinical studies (London et al., 2013). Overall, functional recovery after nerve injury is a multistep process involving cell survival, axonal regeneration, axonal guidance to the appropriate target, connectivity to the target and restoration of function (Horner and Gage, 2000; Aguayo, 2009). This requires, as Cajal noted, to "give to the sprouts, by means of adequate alimentation, a vigorous capacity for growth" (Ramón y Cajal, 1968). 


\section{APPENDICES}

Appendix A. Mean number of outgrowing fibers that grew past different distances from the edges of the retinal explants exposed to different treatments.

\begin{tabular}{|c|c|c|c|c|c|}
\hline & \multicolumn{5}{|c|}{ Number of outgrowing fibers (mean \pm SEM) } \\
\hline & $>50 \mu \mathrm{m}$ & $>100 \mu \mathrm{m}$ & $>150 \mu \mathrm{m}$ & $>200 \mu \mathrm{m}$ & $>300 \mu \mathrm{m}$ \\
\hline Vehicle & $\begin{array}{l}51 \pm \\
16.65\end{array}$ & $\begin{array}{c}33.67 \pm \\
16.28\end{array}$ & $\begin{array}{c}20.75 \pm \\
11.43\end{array}$ & $\begin{array}{c}11.33 \pm \\
6.63\end{array}$ & $\begin{array}{c}0.83 \pm \\
0.83\end{array}$ \\
\hline $\begin{array}{c}0.02 \mathrm{ng} / \mathrm{mL} \\
\text { GM-CSF }\end{array}$ & $\begin{array}{c}33.58 \pm \\
7.55\end{array}$ & $\begin{array}{c}16.25 \pm \\
4.42\end{array}$ & $\begin{array}{l}7.25 \pm \\
3.78\end{array}$ & $\begin{array}{c}2.67 \pm \\
1.51\end{array}$ & 0 \\
\hline $\begin{array}{c}0.2 \mathrm{ng} / \mathrm{mL} \\
\text { GM-CSF }\end{array}$ & $\begin{array}{c}36.83 \pm \\
13.16\end{array}$ & $\begin{array}{c}15.42 \pm \\
8.32\end{array}$ & $\begin{array}{c}6.25 \pm \\
5.81\end{array}$ & $\begin{array}{c}3.17 \pm \\
3.06\end{array}$ & $\begin{array}{l}0.5 \pm \\
0.40\end{array}$ \\
\hline $\begin{array}{l}2 \mathrm{ng} / \mathrm{mL} \\
\text { GM-CSF }\end{array}$ & $\begin{array}{c}56 \pm \\
12.29\end{array}$ & $\begin{array}{c}42.5 \pm \\
10.80\end{array}$ & $\begin{array}{c}28.83 \pm \\
8.40\end{array}$ & $\begin{array}{c}19.5 \pm \\
7.22\end{array}$ & $\begin{array}{c}8.33 \pm \\
4.19\end{array}$ \\
\hline $\begin{array}{l}20 \mathrm{ng} / \mathrm{mL} \\
\text { GM-CSF }\end{array}$ & $\begin{array}{c}53.83 \pm \\
6.82\end{array}$ & $\begin{array}{c}44.58 \pm \\
8.60\end{array}$ & $\begin{array}{c}28.5 \pm \\
5.83\end{array}$ & $\begin{array}{c}16.33 \pm \\
5.34\end{array}$ & $\begin{array}{c}3.5 \pm \\
1.51\end{array}$ \\
\hline $\begin{array}{c}200 \mathrm{ng} / \mathrm{mL} \\
\text { GM-CSF }\end{array}$ & $\begin{array}{c}59.08 \pm \\
5.69\end{array}$ & $\begin{array}{c}53.92 \pm \\
7.51\end{array}$ & $\begin{array}{c}40.08 \pm \\
5.85\end{array}$ & $\begin{array}{c}34.08 \pm \\
4.79\end{array}$ & $\begin{array}{c}17.83 \pm \\
2.60\end{array}$ \\
\hline
\end{tabular}

$n=4$ per treatment 
Appendix B. Median number of outgrowing fibers that grew past different distances from the edges of the retinal explants exposed to different treatments.

\begin{tabular}{|c|c|c|c|c|c|}
\hline \multirow{2}{*}{} & \multicolumn{5}{|c|}{ Number of outgrowing fibers (median) } \\
\cline { 2 - 6 } & $>\mathbf{5 0} \boldsymbol{\mu m}$ & $>\mathbf{1 0 0} \boldsymbol{\mu m}$ & $>\mathbf{1 5 0} \boldsymbol{\mu m}$ & $>\mathbf{2 0 0} \boldsymbol{\mu m}$ & $>\mathbf{3 0 0} \boldsymbol{\mu m}$ \\
\hline Vehicle & 57.5 & 33 & 20.5 & 10 & 0 \\
\hline $\begin{array}{c}\mathbf{0 . 0 2} \mathbf{~ n g / m L} \\
\text { GM-CSF }\end{array}$ & 31.83 & 13.67 & 4.67 & 1.84 & 0 \\
\hline $\begin{array}{c}\mathbf{0 . 2} \mathbf{~ n g} / \mathbf{m L} \\
\text { GM-CSF }\end{array}$ & 27.5 & 9.83 & 0.67 & 0.17 & 0.17 \\
\hline $\begin{array}{c}\mathbf{2} \mathbf{~ n g} / \mathbf{m L} \\
\text { GM-CSF }\end{array}$ & 58.83 & 43.33 & 29.33 & 21.17 & 8.50 \\
\hline $\begin{array}{c}\mathbf{2 0} \mathbf{~ n g} / \mathbf{m L} \\
\text { GM-CSF }\end{array}$ & 49 & 40.17 & 28.83 & 16.5 & 3.33 \\
\hline $\begin{array}{c}\mathbf{2 0 0} \mathbf{~ n g / m L} \\
\text { GM-CSF }\end{array}$ & 59.17 & 55 & 40.17 & 34.34 & 18 \\
\hline
\end{tabular}

$n=4$ per treatment 


\section{REFERENCES}

Aguayo, A. J. et al. Synaptic connections made by axons regenerating in the central nervous system of adult mammals. J. Exp. Biol. 153, 199-224 (1990).

Aguayo, A. J. Neural repair. http://cme.mcgill.ca/php/hom.php?id=1109 (2009).

Aguayo, A. J., Vidal-Sanz, M., Villegas-Pérez, M. P. \& Bray, G. M. Growth and connectivity of axotomized retinal neurons in adult rats with optic nerves substituted by PNS grafts linking the eye and the midbrain. Ann. N. Y. Acad. Sci. 495, 1-9 (1987).

Alilain, W. J., Horn, K. P., Hu, H., Dick, T. E. \& Silver, J. Functional regeneration of respiratory pathways after spinal cord injury. Nature 475, 196-200 (2011).

Alto, L. T. et al. Chemotropic guidance facilitates axonal regeneration and synapse formation after spinal cord injury. Nat. Neurosci. 12, 1106-1113 (2009).

Asomugha, C. O., Linn, D. M. \& Linn, C. L. ACh receptors link two signaling pathways to neuroprotection against glutamate-induced excitotoxicity in isolated RGCs. $J$. Neurochem. 112, 214-216 (2010).

Bähr, M., Vanselow, J. \& Thanos, S. In vitro regeneration of adult rat ganglion cell axons from retinal explants. Exp. Brain Res. 73, 393-401 (1988).

Baldwin, G. C., Benveniste, E. N., Chung, G. Y., Gasson, J. C. \& Golde, D. W. Identification and characterization of a high-affinity granulocyte-macrophage colony-stimulating factor receptor on primary rat oligodendrocytes. Blood 82, 3279-3282 (1993). 
Bareyre, F. M. et al. In vivo imaging reveals a phase-specific role of STAT3 during central and peripheral nervous system axon regeneration. Proc. Natl. Acad. Sci. USA 108, 6282-6287 (2011).

Barton, W. A. et al. Structure and axon outgrowth inhibitor binding of the Nogo-66 receptor and related proteins. EMBO J. 22, 3291-3302 (2003).

Bartsch, U. et al. Lack of evidence that myelin-associated glycoprotein is a major inhibitor of axonal regeneration in the CNS. Neuron 15, 1375-1381 (1995).

Belin, S. et al. Injury-induced decline of intrinsic regenerative ability revealed by quantitative proteomics. Neuron 86, 1000-1014 (2015).

Benowitz, L. I. \& Yin, Y. Combinatorial treatments for promoting axon regeneration in the CNS: strategies for overcoming inhibitory signals and activating neurons' intrinsic growth state. Dev. Neurobiol. 67, 1148-1165 (2007).

Berkelaar, M., Clarke, D. B., Wang, Y. C., Bray, G. M. \& Aguayo, A. J. Axotomy results in delayed death and apoptosis of retinal ganglion cells in adult rats. J. Neurosci. 14, 4368-4374 (1994).

Bertrand, J., Winton, M. J., Rodriguez-Hernandez, N., Campenot, R. B. \& McKerracher, L. Application of Rho antagonist to neuronal cell bodies promotes neurite growth in compartmented cultures and regeneration of retinal ganglion cell axons in the optic nerve of adult rats. J. Neurosci. 25, 1113-1121 (2005).

Bianchi, M., Clavenna, A., Bondiolotti, G. P., Ferrario, P. \& Panerai, A. E. GM-CSF affects hypothalamic neurotransmitter levels in mice: involvement of interleukin1. Neuroreport 8, 3587-3590 (1997). 
Biernaskie, J. et al. Skin-derived precursors generate myelinating Schwann cells that promote remyelination and functional recovery after contusion spinal cord injury. J. Neurosci. 27, 9545-9559 (2007).

Böcker-Meffert, S. et al. Erythropoietin and VEGF promote neural outgrowth from retinal explants in postnatal rats. Invest. Ophthalmol. Vis. Sci. 43, 2021-2026 (2002).

Bouchard, J. F. et al. Protein kinase A activation promotes plasma membrane insertion of DCC from an intracellular pool: a novel mechanism regulating commissural axon extension. J. Neurosci. 24, 3040-3050 (2004).

Bouhy, D. et al. Delayed GM-CSF treatment stimulates axonal regeneration and functional recovery in paraplegic rats via an increased BDNF expression by endogenous macrophages. FASEB J. 20, 1239-1241 (2006).

Bradbury, E. J. et al. Chondroitinase $\mathrm{ABC}$ promotes functional recovery after spinal cord injury. Nature 416, 636-640 (2002).

Bradke, F., Fawcett, J. W. \& Spira, M. E. Assembly of a new growth cone after axotomy: the precursor to axon regeneration. Nat. Rev. Neurosci. 13, 183-193 (2012).

Bregman, B. S. et al. Recovery from spinal cord injury mediated by antibodies to neurite growth inhibitors. Nature 378, 498-501 (1995).

Brown, J. \& Bridgman, P. C. Role of myosin II in axon outgrowth. J. Histochem. Cytochem. 51, 421-428 (2003).

Brunet, I. et al. The transcription factor Engrailed-2 guides retinal axons. Nature 438, 9498 (2005). 
Bull, N. D., Johnson, T. V. \& Martin, K. R. Organotypic explant culture of adult rat retina for in vitro investigations of neurodegeneration, neuroprotection and cell transplantation. Protocol Exchange doi: 10.1038/protex.2011.215 (2011).

Burgess, A. W. \& Metcalf, D. The nature and action of granulocyte-macrophage colony stimulating factors. Blood 56, 947-958 (1980).

Cai, D. et al. Neuronal cyclic AMP controls the developmental loss in ability of axons to regenerate. J. Neurosci. 21, 4731-4739 (2001).

Cayouette, M. Spécification cellulaire: développement de la rétine. http://www.ircm.qc.ca/Etudier/cours/Documents/Cayouette_March2013.pdf (2013).

Cayouette, M. \& Raff, M. The orientation of cell division influences cell-fate choice in the developing mammalian retina. Development 130, 2329-2339 (2003).

Cepko, C. Intrinsically different retinal progenitor cells produce specific types of progeny. Nat. Rev. Neurosci. 15, 615-627 (2014).

Chao, M. V. Neurotrophins and their receptors: a convergence point for many signalling pathways. Nat. Rev. Neurosci. 4, 299-309 (2003).

Chen, D. F., Jhaveri, S. \& Schneider, G. E. Intrinsic changes in developing retinal neurons result in regenerative failure of their axons. Proc. Natl. Acad. USA 92, 7287-7291 (1995).

Chen, D. F., Schneider, G. E., Martinou, J. C. \& Tonegawa, S. Bcl-2 promotes regeneration of severed axons in mammalian CNS. Nature 385, 434-439 (1997).

Chen, M. S. et al. Nogo-A is a myelin-associated neurite outgrowth inhibitor and an antigen for monoclonal antibody IN-1. Nature 403, 434-439 (2000). 
Choi, J. K. et al. GM-CSF reduces expression of chondroitin sulfate proteoglycan (CSPG) core proteins in TGF- $\beta$-treated primary astrocytes. BMB Rep. 47, 679$684(2014 a)$.

Choi, J. K. et al. Signal transduction pathways of GM-CSF in neural cell lines. Neurosci. Lett. 420, 217-222 (2007).

Choi, J. K., Kim, K. H., Park, H., Park, S. R. \& Choi, B. H. Granulocyte macrophagecolony stimulating factor shows anti-apoptotic activity in neural progenitor cells via JAK/STAT5-Bcl2-pathway. Apoptosis 16, 127-134 (2011).

Choi, J. K., Kim, K. H., Park, S. R. \& Choi, B. H. Granulocyte macrophage colonystimulating factor shows anti-apoptotic activity via the PI3K-NF-KB-HIF-1 $\alpha$ survivin pathway in mouse neural progenitor cells. Mol. Neurobiol. 49, 724-733 (2014b).

Chung, J. et al. Effects of granulocyte colony-stimulating factor and granulocytemacrophage colony-stimulating factor on glial scar formation after spinal cord injury in rats. J. Neurosurg. Spine 21, 966-973 (2014).

Dame, J. B., Christensen, R. D. \& Juul, S. E. The distribution of granulocytemacrophage colony-stimulating factor and its receptor in the developing human fetus. Pediatr. Res. 46, 358-366 (1999).

David, S. \& Aguayo, A. J. Axonal elongation into peripheral nervous system "bridges" after central nervous system injury in adult rats. Science 214, 931-933 (1981).

de Lima, S. et al. Full-length axon regeneration in the adult mouse optic nerve and partial recovery of simple visual behaviors. Proc. Natl. Acad. Sci. USA 109, 9149-9154 (2012). 
Dergham, P. et al. Rho signaling pathway targeted to promote spinal cord repair. $J$. Neurosci. 22, 6570-6577 (2002).

Dickendesher, T. L. et al. $\mathrm{NgR} 1$ and $\mathrm{NgR} 3$ are receptors for chondroitin sulfate proteoglycans. Nat. Neurosci. 15, 703-712 (2012).

Diederichs, K., Boone, T. \& Karplus, P. A. Novel fold and putative receptor binding site of granulocyte-macrophage colony-stimulating factor. Science 254, 1779-1782 (1991).

Domeniconi, M. et al. Myelin-associated glycoprotein interacts with the Nogo66 receptor to inhibit neurite outgrowth. Neuron 35, 283-290 (2002).

Donovan, S. L. \& Dyer, M. A. Preparation and square wave electroporation of retinal explant cultures. Nat. Protoc. 1, 2710-2718 (2006).

Dranoff, G. et al. Involvement of granulocyte-macrophage colony-stimulating factor in pulmonary homeostasis. Science 264, 713-716 (1994).

$\mathrm{Du}, \mathrm{K}$. et al. Pten deletion promotes regrowth of corticospinal tract axons 1 year after spinal cord injury. J. Neurosci. 35, 9754-9763 (2015).

Duan, X. et al. Subtype-specific regeneration of retinal ganglion cells following axotomy: effects of osteopontin and mTOR signaling. Neuron 85, 1244-1256 (2015).

Elmore, S. Apoptosis: a review of programmed cell death. Toxicol. Pathol. 35, 495-516 (2007).

Ertürk, A., Hellal, F., Enes, J. \& Bradke F. Disorganized microtubules underlie the formation of retraction bulbs and the failure of axonal regeneration. $J$ Neurosci. 27, 9169-9180 (2007). 
Fabbro, D. BCR-ABL signaling: A new STATus in CML. Nat. Chem. Biol. 8, 228-229 (2012).

Fawcett, J. W., Housden, E., Smith-Thomas, L. \& Meyer RL. The growth of axons in three-dimensional astrocyte cultures. Dev. Biol. 135, 449-458 (1989).

Filbin, M. T. Myelin-associated inhibitors of axonal regeneration in the adult mammalian CNS. Nat. Rev. Neurosci. 4, 703-713 (2003).

Filous, A. R. et al. Immature astrocytes promote CNS axonal regeneration when combined with chondroitinase ABC. Dev. Neurobiol. 70, 826-841 (2010).

Fischer, D. \& Leibinger, M. Promoting optic nerve regeneration. Prog. Retin. Eye Res. 31, 688-701 (2012).

Fischer, D., Hauk, T. G., Müller, A \& Thanos, S. Crystallins of the $\beta / \gamma$-superfamily mimic the effects of lens injury and promote axon regeneration. Mol. Cell. Neurosci. 37, 471-479 (2008).

Fischer, D., He, Z. \& Benowitz, L. I. Counteracting the Nogo receptor enhances optic nerve regeneration if retinal ganglion cells are in an active growth state. $J$. Neurosci. 24, 1646-1651 (2004a).

Fischer, D., Petkova, V., Thanos, S. \& Benowitz, L. I. Switching mature retinal ganglion cells to a robust growth state in vivo: gene expression and synergy with RhoA inactivation. J. Neurosci. 24, 8726-8740 (2004b).

Fischer, H. G. et al. Differentiation driven by granulocyte-macrophage colonystimulating factor endows microglia with interferon-gamma-independent antigen presentation function. J. Neuroimmunol. 42, 87-95 (1993). 
Fleetwood, A.J., Cook A.D. \& Hamilton, J.A. Functions of granulocyte-macrophage colony-stimulating factor. Crit. Rev. Immunol. 25, 405-428 (2005).

Fleischmann, J., Golde, D. W., Weisbart, R. H. \& Gasson, J. C. Granulocyte-macrophage colony-stimulating factor enhances phagocytosis of bacteria by human neutrophils. Blood 68, 708-711 (1986).

Fournier, A. E. CNS regeneration: molecular approaches to identify novel therapeutic strategies for nerve injury. http://cme.mcgill.ca/php/hom.php?id=1113 (2009).

Fournier, A. E., GrandPré, T. \& Strittmatter, S. M. Identification of a receptor mediating Nogo-66 inhibition of axonal regeneration. Nature 409, 341-346 (2001).

Fournier, A. E., Takizawa, B. T. \& Strittmatter, S. M. Rho kinase inhibition enhances axonal regeneration in the injured CNS. J. Neurosci. 23, 1416-1423 (2003).

Frank, T. et al. Both systemic and local application of granulocyte-colony stimulating factor (G-CSF) is neuroprotective after retinal ganglion cell axotomy. BMC Neurosci. 10, 49 (2009).

Franzen, R., Bouhy, D. \& Schoenen, J. Nervous system injury: focus on the inflammatory cytokine 'granulocyte-macrophage colony stimulating factor'. Neurosci. Lett. 361, 76-78 (2004).

García-Alías, G., Barkhuysen, S., Buckle, M. \& Fawcett, J. W. Chondroitinase ABC treatment opens a window of opportunity for task-specific rehabilitation. Nat. Neurosci. 12, 1145-1151 (2009).

Gasson, J. C. Molecular physiology of granulocyte-macrophage colony-stimulating factor. Blood 77, 1131-1145 (1991). 
Gaublomme, D., Buyens, T. \& Moons, L. Automated analysis of neurite outgrowth in mouse retinal explants. J. Biomol. Screen. 18, 534-543 (2013).

Giger, R. J., Hollis, E. R. II, \& Tuszynski, M. H. Guidance molecules in axon regeneration. Cold Spring Harb. Perspect. Biol. 2, a001867 (2010).

Gogvadze, V., Orrenius, S. \& Zhivotovsky, B. Multiple pathways of cytochrome c release from mitochondria in apoptosis. Biochim. Biophys. Acta 1757, 639-647 (2006).

Goldberg, J. L., Klassen, M. P., Hua, Y. \& Barres, B. A. Amacrine-signaled loss of intrinsic axon growth ability by retinal ganglion cells. Science 296, 1860-1864 (2002).

GrandPré, T., Li, S. \& Strittmatter, S. M. Nogo-66 receptor antagonist peptide promotes axonal regeneration. Nature 417, 547-551 (2002).

GrandPré, T., Nakamura, F., Vartanian, T. \& Strittmatter, S. M. Identification of the Nogo inhibitor of axon regeneration as a Reticulon protein. Nature 403, 439-444 (2000).

Gray, H. Gray's Anatomy: The Classical Collector's Edition (eds. Pick, T. P. \& Howden, R.) (Bounty Books, New York, 1977).

Guan, K. L. \& Rao, Y. Signalling mechanisms mediating neuronal responses to guidance cues. Nat. Rev. Neurosci. 4, 941-956 (2003).

Guo, Y. et al. Granulocyte colony-stimulating factor improves neuron survival in experimental spinal cord injury by regulating nucleophosmin-1 expression. $J$. Neurosci. Res. 92, 751-760 (2014). 
Gwilz. Vector diagram of laboratory mouse (black and white). https://commons.wikimedia.org/wiki/File:Vector_diagram_of_laboratory_mouse_ (black_and_white).svg (2013).

Ha, Y. et al. Role of granulocyte-macrophage colony-stimulating factor in preventing apoptosis and improving functional outcome in experimental spinal cord contusion injury. J. Neurosurg. Spine 2, 55-61 (2005).

Halfter, W., Newgreen, D. F., Sauter, J. \& Schwarz, U. Oriented axon outgrowth from avian embryonic retinae in culture. Dev. Biol. 95, 56-64 (1983).

Hamilton, J. A. Colony-stimulating factors in inflammation and autoimmunity. Nat. Rev. Immunol. 8, 533-544 (2008).

Handman, E. \& Burgess, A. W. Stimulation by granulocyte-macrophage colonystimulating factor of Leishmania tropica killing by macrophages. J. Immunol. 122, 1134-1137 (1979).

Harel, N. Y. \& Strittmatter, S. M. Can regenerating axons recapitulate developmental guidance during recovery from spinal cord injury? Nat. Rev. Neurosci. 7, 603-616 (2006).

Hatakeyama, J. \& Kageyama, R. Retrovirus-mediated gene transfer to retinal explants. Methods 28, 387-395 (2002).

Hawthorne, A. L. et al. The unusual response of serotonergic neurons after CNS injury: lack of axonal dieback and enhanced sprouting within the inhibitory environment of the glial scar. J. Neurosci. 31, 5606-5616 (2011).

Hay, N. \& Sonenberg, N. Upstream and downstream of mTOR. Genes Dev. 18, 19261945 (2004). 
Hayashida, K. et al. Molecular cloning of a second subunit of the receptor for human granulocyte-macrophage colony-stimulating factor (GM-CSF): reconstitution of a high-affinity GM-CSF receptor. Proc. Natl. Acad. Sci. USA 87, 9655-9659 (1990).

Heiduschka, P., Fischer, D. \& Thanos, S. Recovery of visual evoked potentials after regeneration of cut retinal ganglion cell axons within the ascending visual pathway in adult rats. Restor. Neurol. Neurosci. 23, 303-312 (2005).

Hercus, T. R. et al. The granulocyte-macrophage colony-stimulating factor receptor: linking its structure to cell signaling and its role in disease. Blood 114, 1289-1298 (2009).

Horner, P. J. \& Gage, F. H. Regenerating the damaged central nervous system. Nature 407, 963-970 (2000).

Huang, X. et al. GM-CSF inhibits apoptosis of neural cells via regulating the expression of apoptosis-related proteins. Neurosci. Res. 58, 50-57 (2007).

Huang, X. et al. GM-CSF inhibits glial scar formation and shows long-term protective effect after spinal cord injury. J. Neurol. Sci. 277, 87-97 (2009).

Huber, A. B., Kolodkin, A. L., Ginty, D. D. \& Cloutier J. F. Signaling at the growth cone: ligand-receptor complexes and the control of axon growth and guidance. Annu. Rev. Neurosci. 26, 509-563 (2003).

Huebner, E. A. \& Strittmatter, S. M. Axon Regeneration in the Peripheral and Central Nervous Systems. Results Probl. Cell Differ. 48, 339-351 (2009).

Jo, S. A., Wang, E. \& Benowitz, L. I. Ciliary neurotrophic factor is an axogenesis factor for retinal ganglion cells. Neuroscience 89, 579-591 (1999). 
Johnson, T. V. \& Martin, K. R. Development and characterization of an adult retinal explant organotypic tissue culture system as an in vitro intraocular stem cell transplantation model. Invest. Ophthalmol. Vis. Sci. 49, 3503-3512 (2008).

Jolicoeur, C. \& Cayouette, M. Retinal explant culture. Bio-protocol 4, e1032 (2014).

Kamegai, M., Konishi, Y. \& Tabira T. Trophic effect of granulocyte-macrophage colonystimulating factor on central cholinergic neurons in vitro. Brain Res. 532, 323-325 (1990).

Kannan, Y., Bienenstock, J., Ohta, M., Stanisz, A. M. \& Stead, R. H. Nerve growth factor and cytokines mediate lymphoid tissue-induced neurite outgrowth from mouse superior cervival ganglia in vitro. J. Immunol. 157, 313-320 (1996).

Kannan, Y. et al. Neurotrophic action of interleukin 3 and granulocytemacrophage colony-stimulating factor on murine sympathetic neurons. Neuroimmunomodulation 8, 132-141 (2000).

Kent, C. B. et al. 14-3-3 proteins regulate protein kinase a activity to modulate growth cone turning responses. J. Neurosci. 30, 14059-14067 (2010).

Kim, H. J. et al. Hypoxia-specific GM-CSF-overexpressing neural stem cells improve graft survival and functional recovery in spinal cord injury. Gene Ther. 19, 513521 (2012).

Kim, J. E., Li, S., GrandPré, T., Qiu, D. \& Strittmatter, S. M. Axon regeneration in young adult mice lacking nogo-a/b. Neuron 38, 187-199 (2003). 
Kim, N. K. et al. Granulocyte-macrophage colony-stimulating factor promotes survival of dopaminergic neurons in the 1-methyl-4-phenyl-1,2,3,6-tetrahydropyridineinduced murine Parkinson's disease model. Eur. J. Neurosci. 29, 891-900 (2009).

Kimura, M., Kodama, T., Aguila, M. C., Zhang, S. Q. \& Inoue, S. Granulocytemacrophage colony-stimulating factor modulates rapid eye movement (REM) sleep and non-REM sleep in rats. J. Neurosci. 20, 5544-5551 (2000).

Koizumi, A., Zeck, G., Ben, Y., Masland, R. H \& Jakobs, T. C. Organotypic culture of physiologically functional adult mammalian retinas. PLoS One 2, e221 (2007).

Kolb, H. Glial cells of the retina. http://webvision.med.utah.edu/book/part-ii-anatomyand-physiology-of-the-retina/glial-cells-of-the-retina (2013).

Kottis, V. et al. Oligodendrocyte-myelin glycoprotein (OMgp) is an inhibitor of neurite outgrowth. J. Neurochem. 82, 1566-1569 (2002).

Kretz, A., Marticke, J. K., Happold, C. J., Schmeer, C. \& Isenmann, S. A primary culture technique of adult retina for regeneration studies on adult CNS neurons. Nat. Protoc. 2, 131-140 (2007).

Krieger, M. et al. The hematopoietic cytokine granulocyte-macrophage colony stimulating factor is important for cognitive functions. Sci. Rep. 2, 697 (2012).

Lamb, T. D., Collin, S. P. \& Pugh, E. N. Jr. Evolution of the vertebrate eye: opsins, photoreceptors, retina and eye cup. Nat. Rev. Neurosci. 8, 960-976 (2007).

Lang, R. A. et al. Transgenic mice expressing a hemopoietic growth factor gene (GMCSF) develop accumulations of macrophages, blindness, and a fatal syndrome of tissue damage. Cell 51, 675-686 (1987). 
Lee, J. K. et al. Assessing spinal axon regeneration and sprouting in Nogo-, MAG-, and OMgp-deficient mice. Neuron 66, 663-670 (2010a).

Lee, J. K. et al. Combined genetic attenuation of myelin and semaphorin-mediated growth inhibition is insufficient to promote serotonergic axon regeneration. $J$. Neurosci. 30, 10899-10904 (2010b).

Lee, S. C., Liu, W., Brosnan, C. F. \& Dickson, D. W. GM-CSF promotes proliferation of human fetal and adult microglia in primary cultures. Glia 12, 309-318 (1994).

Legacy, J., Hanea, S., Theoret, J. \& Smith, P. D. Granulocyte macrophage colonystimulating factor promotes regeneration of retinal ganglion cells in vitro through a mammalian target of rapamycin-dependent mechanism. J. Neurosci. Res. 91, 771-779 (2013).

Lehmann, M. et al. Inactivation of Rho signaling pathway promotes CNS axon regeneration. J. Neurosci. 19, 7537-7547 (1999).

Leon, S., Yin, Y., Nguyen, J., Irwin., N. \& Benowitz, L. I. Lens injury stimulates axon regeneration in the mature rat optic nerve. J. Neurosci. 20, 4615-4626 (2000).

Leung, K. M. et al. Asymmetrical beta-actin mRNA translation in growth cones mediates attractive turning to netrin-1. Nat. Neurosci. 9, 1247-1256 (2006).

Li, P. et al. Cytochrome c and dATP-dependent formation of Apaf-1/caspase-9 complex initiates an apoptotic protease cascade. Cell 91, 479-489 (1997).

Li, S. et al. Injured adult retinal axons with Pten and Socs3 co-deletion reform active synapses with suprachiasmatic neurons. Neurobiol. Dis. 73C, 366-376 (2014). 
Lin, Y. P., Ouchi, Y., Satoh, S. \& Watanabe, S. Sox2 plays a role in the induction of amacrine and Müller glial cells in mouse retinal progenitor cells. Invest. Ophthalmol. Vis. Sci. 50, 68-74 (2009).

Liu, K. et al. PTEN deletion enhances the regenerative ability of adult corticospinal neurons. Nat. Neurosci. 13, 1075-1081 (2010).

Liu, K., Tedeschi, A., Park, K. K. \& He, Z. Neuronal intrinsic mechanisms in axon regeneration. Annu. Rev. Neurosci. 34, 131-152 (2011).

Liu, R. Y. \& Snider W. D. Different signaling pathways mediate regenerative versus developmental sensory axon growth. J. Neurosci. 21, RC164 (2001).

London, A., Benhar, I. \& Schwartz, M. The retina as a window to the brain-from eye research to CNS disorders. Nat. Rev. Neurol. 9, 44-53 (2013).

Lowery, L. A. \& Van Vactor, D. The trip of the tip: understanding the growth cone machinery. Nat. Rev. Mol. Cell. Biol. 10, 332-343 (2009).

$\mathrm{Lu}$, P. et al. Long-distance axonal growth from human induced pluripotent stem cells after spinal cord injury. Neuron 83, 789-796 (2014).

Lukashenko, P. V., Lukashenko, T. M., Savanovich, I. I., Sandakov, D. B. \& Gerein, V. Granulocyte macrophage colony-stimulating factor regulates activity of the nervous system. Neuroimmunomodulation 11, 36-40 (2004).

Luo, J. Colony-stimulating factor 1 receptor (CSF1R) signaling in injured neurons facilitates protection and survival. J. Exp. Med. 210, 157-172 (2013).

Luo, L. Actin cytoskeleton regulation in neuronal morphogenesis and structural plasticity. Annu. Rev. Cell Dev. Biol. 18, 601-635 (2002). 
Mackay, D. J., Nobes, C. D. \& Hall, A. The Rho's progress: a potential role during neuritogenesis for the Rho family of GTPases. Trends Neurosci. 18, 496-501 (1995).

Mangano, E. N. et al. Granulocyte macrophage-colony stimulating factor protects against substantia nigra dopaminergic cell loss in an environmental toxin model of Parkinson's disease. Neurobiol. Dis. 43, 99-112 (2011).

McKernan, D. P., Caplis, C., Donovan, M., O'brien, C.J. \& Cotter, T. G. Age-dependent susceptibility of the retinal ganglion cell layer to cell death. Invest. Ophthalmol. Vis. Sci. 47, 807-814 (2006).

McKerracher, L. et al. Identification of myelin-associated glycoprotein as a major myelin-derived inhibitor of neurite growth. Neuron 13, 805-811 (1994).

McLay, R. N., Kimura, M., Banks, W. A. \& Kastin, A. J. Granulocyte-macrophage colony-stimulating factor crosses the blood--brain and blood--spinal cord barriers. Brain 120, 2083-2091 (1997).

Mi, S. et al. LINGO-1 is a component of the Nogo-66 receptor/p75 signaling complex. Nat. Neurosci. 7, 221-228 (2004).

Monnier, P. P., Sierra, A., Schwab, J. M., Henke-Fahle, S. \& Mueller, B. K. The Rho/ROCK pathway mediates neurite growth-inhibitory activity associated with the chondroitin sulfate proteoglycans of the CNS glial scar. Mol. Cell. Neurosci. 22, 319-330 (2003).

Moon, L. D., Asher, R. A., Rhodes, K. E. \& Fawcett, J. W. Regeneration of CNS axons back to their target following treatment of adult rat brain with chondroitinase ABC. Nat. Neurosci. 4, 465-466 (2001). 
Moore, D. L. \& Goldberg, J. L. Four steps to optic nerve regeneration. J. Neuroophthalmol. 30, 347-360 (2010).

Moore, D. L. et al. KLF family members regulate intrinsic axon regeneration ability. Science 326, 298-301 (2009).

Mui, A. L., Wakao, H., O'Farrell, A. M., Harada, N. \& Miyajima, A. Interleukin-3, granulocyte-macrophage colony stimulating factor and interleukin-5 transduce signals through two STAT5 homologs. EMBO J. 14, 1166-1175 (1995).

Müller, A, Hauk, T. G. \& Fischer, D. Astrocyte-derived CNTF switches mature RGCs to a regenerative state following inflammatory stimulation. Brain 130, 3308-3320 (2007).

Müller, A., Hauk, T. G., Leibinger, M., Marienfeld, R. \& Fischer, D. Exogenous CNTF stimulates axon regeneration of retinal ganglion cells partially via endogenous CNTF. Mol. Cell. Neurosci. 41, 233-246 (2009).

Murphy, K. Janeway’s Immunobiology Edn. 8 (Garland Science, New York, 2012).

Nash, M., Pribiag, H., Fournier, A. E. \& Jacobson C. Central nervous system regeneration inhibitors and their intracellular substrates. Mol. Neurobiol.40, 224235 (2009).

Neumann, S. \& Woolf, C. J. Regeneration of dorsal column fibers into and beyond the lesion site following adult spinal cord injury. Neuron 23, 83-91 (1999).

Niederöst, B., Oertle, T., Fritsche, J., McKinney, R. A. \& Bandtlow, C. E. Nogo-A and myelin-associated glycoprotein mediate neurite growth inhibition by antagonistic regulation of RhoA and Rac1. J. Neurosci. 22, 10368-10376 (2002). 
Ousman, S. S. \& David, S. MIP-1alpha, MCP-1, GM-CSF, and TNF-alpha control the immune cell response that mediates rapid phagocytosis of myelin from the adult mouse spinal cord. J. Neurosci. 21, 4649-4656 (2001).

Park, J. B. et al. A TNF receptor family member, TROY, is a coreceptor with Nogo receptor in mediating the inhibitory activity of myelin inhibitors. Neuron $\mathbf{4 5}, 345-$ $351(2005)$.

Park, K. K. et al. Promoting axon regeneration in the adult CNS by modulation of the PTEN/mTOR pathway. Science 322, 963-966 (2008).

Peichl, L. Alpha ganglion cells in mammalian retinae: common properties, species differences, and some comments on other ganglion cells. Vis. Neurosci. 7, 155169 (1991).

Piper, M. et al. Signaling mechanisms underlying Slit2-induced collapse of Xenopus retinal growth cones. Neuron 49, 215-228 (2006).

Pool, M., Thiemann, J., Bar-Or, A. \& Fournier, A. E. NeuriteTracer: a novel ImageJ plugin for automated quantification of neurite outgrowth. J. Neurosci. Methods 168, 134-139 (2008).

Prokosch, V., Chiwitt, C., Rose, K. \& Thanos, S. Deciphering proteins and their functions in the regenerating retina. Expert Rev. Proteomics 7, 775-795 (2010).

Qiu, J. et al. Spinal axon regeneration induced by elevation of cyclic AMP. Neuron 13, 895-903 (2002).

Qiu, J., Cafferty, W. B., McMahon, S. B. \& Thompson, S. W. Conditioning injuryinduced spinal axon regeneration requires signal transducer and activator of transcription 3 activation. J. Neurosci. 25, 1645-1653 (2005). 
Quelle, F. W. et al. JAK2 associates with the beta $\mathrm{c}$ chain of the receptor for granulocytemacrophage colony-stimulating factor, and its activation requires the membraneproximal region. Mol. Cell Biol. 14, 4335-4341 (1994).

Ramón y Cajal, S. Degeneration and Regeneration of the Nervous System (trans. and ed. May, R. M.) (Hafner, New York, 1968).

Rapaport, D. H., Wong, L. L., Wood, E. D., Yasumura, D. \& LaVail, M. M. Timing and topography of cell genesis in the rat retina. J. Comp. Neurol. 474, 304-324 (2004).

Raposo, C. \& Schwartz, M. Glial scar and immune cell involvement in tissue remodeling and repair following acute CNS injuries. Glia 62, 1895-1904 (2014).

Rasko, J. E. Granulocyte-macrophage colony-stimulating factor and its receptor. In Colony-Stimulating Factors: Molecular and Cellular Biology Edn. 2 (eds. Garland, J. M., Quesenberry, P. J. \& Hilton, D. J.) 2.10 (Marcel Dekker, Inc., New York, 1997).

Rawlings, J. S., Rosler, K. M. \& Harrison, D. A. The JAK/STAT signaling pathway. J. Cell Sci. 117, 1281-1283 (2004).

Re, F. et al. Granulocyte-macrophage colony-stimulating factor induces an expression program in neonatal microglia that primes them for antigen presentation. $J$. Immunol. 169, 2264-2273 (2002).

Reed, J. A. et al. GM-CSF action in the CNS decreases food intake and body weight. $J$. Clin. Invest. 115, 3035-3044 (2005).

Richardson, P. M. \& Issa, V. M. K. Peripheral injury enhances central regeneration of primary sensory neurons. Nature 309, 791-793 (1984). 
Richardson, P. M., McGuinness, U. M. \& Aguayo, A. J. Axons from CNS neurones regenerate into PNS grafts. Nature 284, 264-265 (1980).

Robinson, S. Diagram of the eye. http://download.videohelp.com/vitualis/med/diagram_of_the_eye.htm (1998).

Root, R. K. \& Dale, D. C. Granulocyte colony-stimulating factor and granulocytemacrophage colony-stimulating factor: comparisons and potential for use in the treatment of infections in nonneutropenic patients. J. Infect. Dis. 179, S342-352 (1999).

Saada, A., Reichert, F. \& Rotshenker S. Granulocyte macrophage colony stimulating factor produced in lesioned peripheral nerves induces the up-regulation of cell surface expression of MAC-2 by macrophages and Schwann cells. J. Cell Biol. 133, 159-167 (1996).

Santiago-Medina, M., Gregus, K. A. \& Gomez, T. M. PAK-PIX interactions regulate adhesion dynamics and membrane protrusion to control neurite outgrowth. J. Cell Sci. 126, 1122-1133 (2013).

Sato, N., Sakamaki, K., Terada, N., Arai, K. \& Miyajima, A. Signal transduction by the high-affinity GM-CSF receptor: two distinct cytoplasmic regions of the common beta subunit responsible for different signaling. EMBO J. 12, 4181-4189 (1993).

Sawada, M., Itoh, Y., Suzumura, A. \& Marunouchi, T. Expression of cytokine receptors in cultured neuronal and glial cells. Neurosci. Lett. 160, 131-134 (1993).

Schäbitz, W. R. et al. A neuroprotective function for the hematopoietic protein granulocyte-macrophage colony stimulating factor (GM-CSF). J. Cereb. Blood Flow Metab. 28, 29-43 (2008). 
Schallenberg, M., Charalambous, P. \& Thanos, S. GM-CSF regulates the ERK 1/2 pathways and protects injured retinal ganglion cells from induced death. Exp. Eye Res. 89, 665-677 (2009).

Schermer, C. \& Humpel C. Granulocyte macrophage-colony stimulating factor activates microglia in rat cortex organotypic brain slices. Neurosci. Lett. 328, 180-184 (2002).

Schmidt, E. V. The role of c-myc in cellular growth control. Oncogene 18, 2988-2996 (1999).

Schneider, A., Kuhn, H. G. \& Schäbitz, W. R. A role for G-CSF (granulocyte-colony stimulating factor) in the central nervous system. Cell Cycle 4, 1753-1757 (2005).

Schnell, L. \& Schwab, M. E. Axonal regeneration in the rat spinal cord produced by an antibody against myelin-associated neurite growth inhibitors. Nature 343, 269$272(1990)$.

Schnell, L. \& Schwab, M. E. Sprouting and regeneration of lesioned corticospinal tract fibres in the adult rat spinal cord. Eur. J. Neurosci. 5, 1156-1171 (1993).

Sepúlveda, P., Encabo, A., Carbonell-Uberos, F. \& Miñana, M. D. BCL-2 expression is mainly regulated by JAK/STAT3 pathway in human CD34+ hematopoietic cells. Cell Death Differ. 14, 378-380 (2007).

Sharma, R. K. \& Netland, P. A. Early born lineage of retinal neurons express class III beta-tubulin isotype. Brain Res.1176, 11-17 (2007)

Shibata, Y. et al. GM-CSF regulates alveolar macrophage differentiation and innate immunity in the lung through PU.1. Immunity 15, 557-567 (2001). 
Shimshoni, J.A. et al. Evaluation of the effects of propylisopropylacetic acid (PIA) on neuronal growth cone morphology. Neuropharmacology 56, 831-837 (2009).

Shuai, K. \& Liu, B. Regulation of JAK-STAT signalling in the immune system. Nat. Rev. Immunol. 3, 900-911 (2003).

Silver, J. \& Miller, J. H. Regeneration beyond the glial scar. Nat. Rev. Neurosci. 5, 146$156(2004)$.

Simonen, M. et al. Systemic deletion of the myelin-associated outgrowth inhibitor NogoA improves regenerative and plastic responses after spinal cord injury. Neuron $\mathbf{3 8}$, 201-211 (2003).

Smith, A. M. et al. M-CSF increases proliferation and phagocytosis while modulating receptor and transcription factor expression in adult human microglia. $J$. Neuroinflammation 10, 85 (2013).

Smith, P. D. et al. SOCS3 deletion promotes optic nerve regeneration in vivo. Neuron 64, $617-623$ (2009).

Song, H. et al. Conversion of neuronal growth cone responses from repulsion to attraction by cyclic nucleotides. Science 281, 1515-1518 (1998).

Sparling, J. S. et al. Schwann cells generated from neonatal skin-derived precursors or neonatal peripheral nerve improve functional recovery after acute transplantation into the partially injured cervical spinal cord of the rat. J. Neurosci. 35, 67146730 (2015).

Stanley, E. et al. Granulocyte/macrophage colony-stimulating factor-deficient mice show no major perturbation of hematopoiesis but develop a characteristic pulmonary pathology. Proc. Natl. Acad. Sci. USA 91, 5592-5596 (1994). 
Sugita, Y. et al. CNS interleukin-3 (IL-3) expression and neurological syndrome in antisense-IL-3 transgenic mice. J. Neuropathol. Exp. Neurol. 58, 480-488 (1999).

Sun, F. et al. Sustained axon regeneration induced by co-deletion of PTEN and SOCS3. Nature 480, 372-375 (2011).

Suzumura, A., Sawada, M., Yamamoto, H. \& Marunouchi, T. Effects of colony stimulating factors on isolated microglia in vitro. J. Neuroimmunol. 30, 111-120 (1990).

Taylor, R. C., Cullen, S. P. \& Martin, S. J. Apoptosis: controlled demolition at the cellular level. Nat. Rev. Mol. Cell. Biol. 9, 231-241 (2008).

Tessier-Lavigne, M. Brain development and brain repair: the life and death of nerve cells. http://bcooltv.mcgill.ca/Viewer2/?RecordingID=35672 (2009).

Tetzlaff, W. et al. A systematic review of cellular transplantation therapies for spinal cord injury. J. Neurotrauma 28, 1611-1682 (2011).

Thorens, B., Mermod, J. J. \& Vassalli, P. Phagocytosis and inflammatory stimuli induce GM-CSF mRNA in macrophages through posttranscriptional regulation. Cell $\mathbf{4 8}$, 671-679 (1987).

Tian, S. S., Lamb, P., Seidel, H. M., Stein, R. B. \& Rosen, J. Rapid activation of the STAT3 transcription factor by granulocyte colony-stimulating factor. Blood $\mathbf{8 4}$, 1760-1764 (1994).

Tom, V. J., Kadakia, R., Santi, L. \& Houlé, J. D. Administration of chondroitinase ABC rostral or caudal to a spinal cord injury site promotes anatomical but not functional plasticity. J. Neurotrauma 26, 2323-2333 (2009). 
Tom, V. J., Steinmetz, M. P., Miller, J. H., Doller, C. M. \& Silver, J. Studies on the development and behavior of the dystrophic growth cone, the hallmark of regeneration failure, in an in vitro model of the glial scar and after spinal cord injury. J. Neurosci. 24, 6531-6539 (2004).

van de Laar, L., Coffer, P. J. \& Woltman, A. M. Regulation of dendritic cell development by GM-CSF: molecular control and implications for immune homeostasis and therapy. Blood 119, 3383-3393 (2012).

Vidal-Sanz, M., Bray, G. M., Villegas-Perez, M. P., Thanos, S., Aguayo, A. J. Axonal regeneration and synapse formation in the superior colliculus by retinal ganglion cells in the adult rat. J Neurosci. 7, 2894-2909 (1987).

Walter, M. R. et al. Three-dimensional structure of recombinant human granulocytemacrophage colony-stimulating factor. J. Mol. Biol. 224, 1075-1085 (1992).

Wang, K. C. et al. Oligodendrocyte-myelin glycoprotein is a Nogo receptor ligand that inhibits neurite outgrowth. Nature 417, 941-944 (2002a).

Wang, K. C., Kim, J. A., Sivasankaran, R., Segal, R \& He, Z. P75 interacts with the Nogo receptor as a co-receptor for Nogo, MAG and OMgp. Nature 420, 74-78 (2002b).

Wang, S. W., Mu, X., Bowers, W. J. \& Klein, W. H. Retinal ganglion cell differentiation in cultured mouse retinal explants. Methods 28, 448-456 (2002).

Watanabe, S., Ishida, S., Koike, K. \& Arai, K. Characterization of cis-regulatory elements of the c-myc promoter responding to human GM-CSF or mouse interleukin 3 in mouse proB cell line BA/F3 cells expressing the human GM-CSF receptor. Mol. Biol. Cell. 6, 627-636 (1995). 
Weisbart, R. H., Golde, D. W., Clark, S. C., Wong, G. G. \& Gasson, J. C. Human granulocyte-macrophage colony-stimulating factor is a neutrophil activator. Nature 314, 361-363 (1985).

Winzeler, A. M. et al. The lipid sulfatide is a novel myelin-associated inhibitor of CNS axon outgrowth. J. Neurosci. 31, 6481-6492 (2011).

Xin, H. et al. A novel organotypic culture model of the postnatal mouse retina allows the study of glutamate-mediated excitotoxicity. J. Neurosci. Methods 159, 35-42 (2007).

Yagihashi, A, Sekiya, T. \& Suzuki, S. Macrophage colony stimulating factor (M-CSF) protects spiral ganglion neurons following auditory nerve injury: morphological and functional evidence. Exp. Neurol. 192, 167-177 (2005).

Yang, E. et al. Bad, a heterodimeric partner for Bcl-XL and Bcl-2, displaces Bax and promotes cell death. Cell 80, 285-291 (1995).

Yin, Y. et al. Macrophage-derived factors stimulate optic nerve regeneration. J. Neurosci. 23, 2284-2293 (2003).

Yin, Y. et al. Oncomodulin is a macrophage-derived signal for axon regeneration in retinal ganglion cells. Nat. Neurosci. 9, 843-852 (2006).

Yin, Y. et al. Oncomodulin links inflammation to optic nerve regeneration. Proc. Natl. Acad. Sci. USA. 106, 19587-19592 (2009).

Yiu, G. \& He, Z. Glial inhibition of CNS axon regeneration. Nat. Rev. Neurosci. 7, 617627 (2006).

Yoon, S. H. et al. Complete spinal cord injury treatment using autologous bone marrow cell transplantation and bone marrow stimulation with granulocyte macrophage- 
colony stimulating factor: Phase I/II clinical trial. Stem Cells 25, 2066-2073 (2007).

Yoon, S. N. et al. Phospholipase D1 mediates bFGF-induced Bcl-2 expression leading to neurite outgrowth in H19-7 cells. Biochem. J. 441, 407-416 (2012).

You, Y. et al. Anti-apoptotic effect of highly secreted GMCSF from neuronal cellspecific GMCSF over-expressing neural stem cells in spinal cord injury model. Spine Epub ahead of print, doi: 10.1097/BRS.0000000000001080 (30 Jul 2015).

Young, R. W. Cell differentiation in the retina of the mouse. Anat. Rec. 212, 199-205 (1985).

Zhang, J. H. \& Xu, M. DNA fragmentation in apoptosis. Cell Research 10, 205-211 (2000).

Zhang, W. \& Liu, H. T. MAPK signal pathways in the regulation of cell proliferation in mammalian cells. Cell Res. 12, 9-18 (2002).

Zhang, Y. et al. PTEN deletion enhances survival, neurite outgrowth and function of dopamine neuron grafts to MitoPark mice. Brain 135, 2736-2749 (2012).

Zheng, B. et al. Genetic deletion of the Nogo receptor does not reduce neurite inhibition in vitro or promote corticospinal tract regeneration in vivo. Proc. Natl. Acad. Sci. USA 102, 1205-1210 (2005). 